Mun Sung Kim

Kwang Hyo Jung

Sung Boo Park

http://dx.doi.org/10.21278/brod69309

ISSN 0007-215X

eISSN $1845-5859$

\title{
WAVE INDUCED COUPLED MOTIONS AND STRUCTURAL LOADS BETWEEN TWO OFFSHORE FLOATING STRUCTURES IN WAVES
}

UDC 629.5(05) 629.563.21:629.5.018.1:629.5.015

Original scientific paper

\begin{abstract}
Summary
As oil or gas field moves deeper offshore area, offshore offloading operations such as Tandem or Side-by-Side arrangement between two floating structures take place in many locations throughout the world and also have many hydrodynamic problems. Therefore, the researches on the motion response and hydrodynamic force including first and second order between two floating structures are needed to have the more safe offloading operability in waves. In this paper, prediction of wave induced motion responses and structural loads at midship section with hydrodynamic interaction effect between two offshore floating structures in various heading waves are studied by using a linearized three-dimensional potential theory. Numerical calculations using three-dimensional pulsating source distribution techniques have been carried out for hydrodynamic pressure distribution, wave exciting force, twelve coupled linear motion responses, relative motions and wave loads of the barge and the ship in oblique waves. The computational results give a good correlation with the experimental results and also with other numerical results. As a result, the present computational tool can be used effectively to predict the wave induced motions and structural loads of multiple offshore floating structures in waves.
\end{abstract}

Key words: coupled motion; hydrodynamic interaction; relative motion; structural loads;

\section{Introduction}

Until now, offshore offloading operations take place in many locations throughout the world. In general, many offshore operations involve the use of two or more floating structures, which are positioned closely to transfer oil or gas during offloading such as oil FPSO and shuttle tanker, and LNG-FPSO and LNG carrier. So they affect each other's motion responses and wave loads through hydrodynamic interaction between two bodies in waves. Consequently, the large motions and wave loads between two floating bodies, which would cause the down time of offloading system failure and damage of ship hull by collision, etc. Because of these serious 
problems during offloading operations, it is very important to study the motion behaviors and wave loads between two offshore floating structures due to the hydrodynamic effect in waves.

However, an experiment of motions and wave loads between two floating structures are very expensive and time-consuming work to design the offshore floating structures in the basic design stage. Therefore, the development of theoretical and numerical prediction program for hydrodynamic pressures, wave exciting forces, motion responses and wave loads between two floating structures are necessary to prudent design for multiple offshore floating structures.

Up to now, not so many authors research have been carried out on the prediction of motion responses of multiple floating structures in waves because this problem is complex. Ohkusu [1] analyzed the motions of a ship in the neighborhood of a large moored two-dimensional floating structure by strip theory. Kodan [2] extended Ohkusu [1]'s theory to hydrodynamic interaction problem between two parallel structures in oblique waves by strip method. Van Oortmerssen [3] and Loken [4] used the three-dimensional linear diffraction theory to solve this problem. Fang and Kim [5] analyzed the motions of two longitudinally parallel barges by strip method. Chen and Fang [6] and Fang and Chen [7] used three-dimensional source distribution method to predict the wave exciting forces and relative motion and wave elevation between two bodies in waves. Inoue and Ali [8] predict the motion and drift force between LNG-FPSO and LNG carrier by using a three-dimensional source sink method in frequency and time domain. Buchner et al [9] developed numerical simulation model for hydrodynamic response of LNG-FPSO with alongside moored LNG carrier in time domain. Choi and Hong [10] used the higher-order boundary element method to analyze the hydrodynamic interaction between multiple floating bodies in waves. Kim et al. [11] developed time-domain approach using Rankine panel method for the multiple-body problem [11]. Recently, Abyn et al. [12] shows the experimental results of hydrodynamic interaction between a Tension Leg Platform (TLP) and semi-submersible in regular waves.

In this paper, we describe the wave induced motion and first and second order structural loads prediction program which have been developed by Kim and Ha [13], Ha and Kim [14, 15] and Kim [16] using three-dimensional linearized potential theory and three-dimensional source distribution technique. The wave loads at a particular ship cross section can be obtained by the integration of external hydrodynamic forces and mass inertia forces on one side of the cut. In order to validate the developed theoretical and numerical calculation program between two floating bodies, the comparisons are performed for Kodan [2]'s experimental and 2-D results, Fang and Kim [5]'s 2-D results and Fang and Chen [6, 7]'s 3-D results for barge and ship, and Pinkster [20]'s experimental results for rectangular barge, respectively.

\section{Theoretical Background and Mathematical Formulation}

To describe the motions responses, the first and second order wave loads between two floating structures in waves, we consider 3 sets of right-handed orthogonal coordinate systems as shown in Fig. 1. O-XYZ is the space fixed coordinate system. $\mathrm{O}_{\mathrm{A}}-\mathrm{X}_{\mathrm{A}} \mathrm{Y}_{\mathrm{A}} \mathrm{Z}_{\mathrm{A}}$ and $\mathrm{O}_{\mathrm{B}}-\mathrm{X}_{\mathrm{B}} \mathrm{Y}_{\mathrm{B}} \mathrm{Z}_{\mathrm{B}}$ are the oscillatory coordinate systems fixed with respect to mean position of ship A and ship B, respectively. The $\mathrm{O}-\mathrm{XY}$ plane coincides with the undisturbed free surface, the $\mathrm{X}$-axis in the direction of the body's forward and the Z-axis vertically upward.

The position vector of a point on the hull of the body relative to the body fixed system axes can be written as follows:

$$
\vec{\alpha}=\vec{\xi}+R_{1} \overrightarrow{r^{\prime}}+R_{2} \overrightarrow{r^{\prime}}+\mathrm{O}\left(\varepsilon^{3}\right)
$$

where $\vec{\alpha}$ represent a small oscillatory displacement and $R_{1}$ and $R_{2}$ are the transformation matrices due to the translational and rotational movement of the body, respectively. 


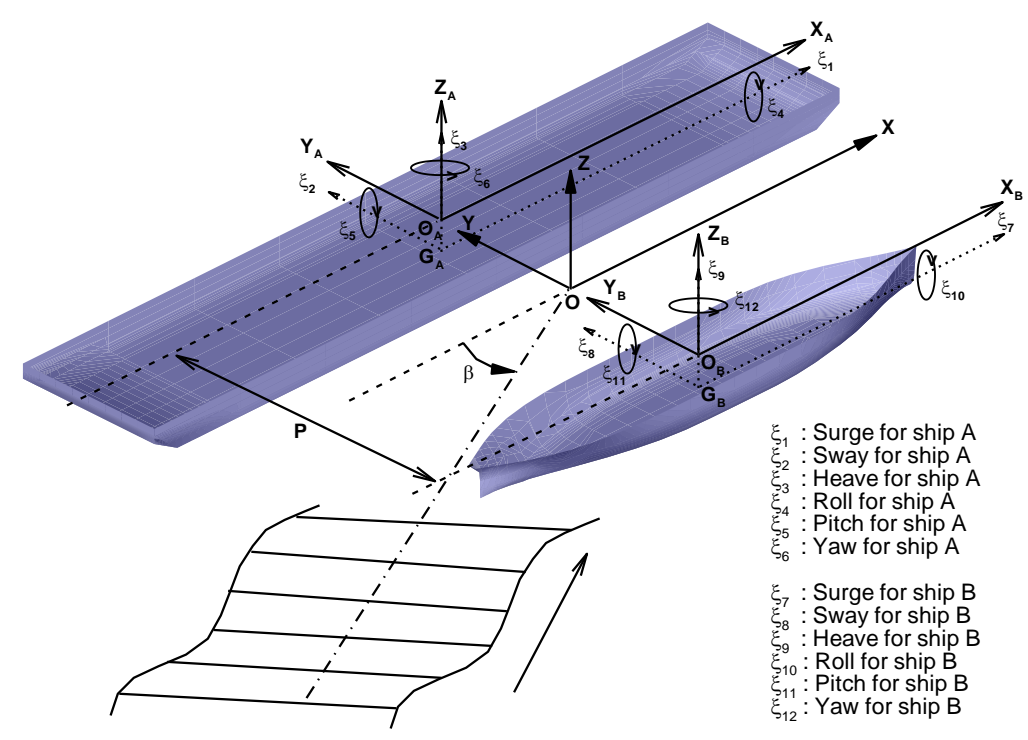

Fig. 1 Definition of Co-ordinate system

The Oscillatory coordinate systems $\mathrm{O}_{\mathrm{A}}-\mathrm{X}_{\mathrm{A}} \mathrm{Y}_{\mathrm{A}} \mathrm{Z}_{\mathrm{A}}$ and $\mathrm{O}_{\mathrm{B}}-\mathrm{X}_{\mathrm{B}} \mathrm{Y}_{\mathrm{B}} \mathrm{Z}_{\mathrm{B}}$ are used to describe the body motion in six degrees of freedom with complex amplitudes $\xi_{j}(j=1,2, \ldots, 12)$. Here $\mathrm{j}=1,2,3,4,5,6$ represent surge, sway, heave, roll, pitch and yaw for ship A, respectively and $\mathrm{j}=7,8,9,10,11,12$ represent surge, sway, heave, roll, pitch and yaw for ship B, respectively as shown in Fig. 1.

The total unsteady potential for a sinusoidal wave excitation with encounter frequency, $\omega_{\mathrm{e}}$, can be expressed as

$$
\phi^{(1)}(x, y, z, t)=\left[\phi_{I}^{(1)}+\phi_{D}^{(1)}+\sum_{j=1}^{12} \xi_{j}^{(1)} \phi_{j}^{(1)}\right] e^{-i \omega_{e} t}
$$

where $\phi_{I}^{(1)}$ is the incident wave potential represent the incident waves; $\phi_{D}{ }^{(1)}$ is the diffraction potential represent the disturbance of the incident waves diffracted from the body; $\phi_{j}^{(1)}(j=1,2, \ldots, 12)$ represent the radiation potentials due to oscillations of the two floating bodies in calm water with unit amplitude.

The incident wave potential was given as follow

$$
\phi_{I}^{(1)}=-\frac{i g \zeta_{a}}{\omega_{o}} e^{k z} e^{i(k x \cos \beta+k y \sin \beta)} e^{-i \omega_{e} t}
$$

where $\omega_{o}$ is the wave frequency, $\zeta_{a}$ the wave amplitude, $k$ the incident wave number, $k=\omega_{o}^{2} / g$, and $\beta$ an arbitrary heading angles ( $180^{\circ}$ for head sea).

The individual potentials have to satisfy in the fluid domain, on the free surface, the submerged body surface, the sea bed and a suitable far-field radiation condition at infinity.

\section{$\underline{\text { Laplace equation }}$}

$$
\nabla^{2} \phi^{(1)}=0 \quad \text { in the fluid domain }
$$

\section{$\underline{\text { Linear free surface condition }}$}




$$
-\omega_{e}^{2} \phi^{(1)}+g \frac{\partial}{\partial z} \phi^{(1)}=0 \quad \text { on } \mathrm{z}=0
$$

$\underline{\text { Body boundary condition for diffraction potentials }}$

$$
\frac{\partial}{\partial n}\left(\phi_{I}^{(1)}+\phi_{D}^{(1)}\right)=0 \quad \text { on ship A and ship B }
$$

$\underline{\text { Body boundary condition for radiation potentials }}$

$$
\begin{aligned}
& \frac{\partial}{\partial n} \phi_{j}^{(1)}=-i \omega_{e} n_{j} \quad(\mathrm{j}=1,2, \ldots, 6) \quad \text { on ship A } \\
& \frac{\partial}{\partial n} \phi_{j}^{(1)}=0 \quad(\mathrm{j}=7,8, \ldots, 12) \quad \text { on ship B } \\
& \frac{\partial}{\partial n} \phi_{j}^{(1)}=0 \quad(\mathrm{j}=1,2, \ldots, 6) \quad \text { on ship A } \\
& \frac{\partial}{\partial n} \phi_{j}^{(1)}=-i \omega_{e} n_{j} \quad(\mathrm{j}=7,8, \ldots, 12) \quad \text { on ship B }
\end{aligned}
$$

where,

$$
\begin{array}{ll}
\left(n_{1}, n_{2}, n_{3}\right)=\vec{n} & \text { on ship A } \\
\left(n_{4}, n_{5}, n_{6}\right)=\vec{r} \times \vec{n} & \text { on ship A } \\
\left(n_{7}, n_{8}, n_{9}\right)=\vec{n} & \text { on ship B } \\
\left(n_{10}, n_{11}, n_{12}\right)=\vec{r} \times \vec{n} & \text { on ship B }
\end{array}
$$

with $\vec{n}$ is the outward unit normal vector on ship A and ship B and $\vec{r}$ is the position vector with respect to the origin of the reference frame on ship A and ship B.

$\underline{\text { Sea bed condition }}$

$$
\frac{\partial}{\partial n} \phi^{(1)}=0 \quad \text { for } \mathrm{z} \rightarrow-\infty
$$

$\underline{\text { Radiation condition at infinity }}$

$$
\lim _{k r \rightarrow \infty} \sqrt{k r}\left(\frac{\partial \phi^{(1)}}{\partial n}-i k \phi^{(1)}\right)=0 \quad \text { at } \mathrm{kr} \rightarrow \infty
$$

The wave force including first and second order can be obtained by the direct integration of the pressure acting on the two-body hull surface in waves. The pressure in the fluid field is obtained by the use of the Bernoulli's equation and expressed in the form as follow,

$$
P=-\rho\left[g z+\frac{1}{2}(\nabla \phi)^{2}+\left(\frac{\partial}{\partial t}-U \frac{\partial}{\partial x}\right) \phi\right]
$$

The total fluid forces and moments acting on the each submerged bodies can be calculated through integration of pressure over a wetted region. 


$$
\vec{F}=\int_{S_{A}+S_{B}} P \vec{n} d s, \quad \vec{M}=\int_{S_{A}+S_{B}} P(\vec{r} \times \vec{n}) d s
$$

The wave exciting force $F_{i}$ can be divided into the incident wave part, $F_{i}^{I}$, and the diffraction part,. $F_{i}^{D}$ in the form excluding speed terms.

$$
F_{i}=F_{i}^{I}+F_{i}^{D}=-i \rho \omega_{e} \iint_{S_{A}+S_{B}}\left(\phi_{I}+\phi_{D}\right) n_{i} d s
$$

To save the computing time and to avoid the numerical error near narrow free surface gap (Newman [17], Malenica et al [18], Zalar et al [19], Chen [21], and Pauw et al [22]) between two floating bodies, Haskind [23] relation is applied in Kim and Ha [13] with various separation distance cases.

$$
F_{i}=-i \rho \omega_{e} \iint_{S_{A}+S_{B}} \phi_{I} n_{i} d s+\rho \iint_{S_{A}+S_{B}} \phi_{j} \frac{\partial \phi_{I}}{\partial n} d s
$$

Expanding the pressure, force and moment as a perturbation expansion series, the zero order and higher order forces can be calculated by collecting terms of same order.

\section{Zero-order Force}

$$
\vec{F}^{(0)}=-\rho g \int_{S_{A}+S_{B}} z \vec{n}^{(0)} d s=(0,0, \rho g V)
$$

where $V$ is the displaced volume of ships. Zero order force is the hydrostatic force due to the buoyancy of an each floating structures.

\section{First-order Force}

$$
\begin{aligned}
& \vec{F}^{(1)}=-\rho \int_{S_{A}+S_{B}}\left(\frac{\partial \phi^{(1)}}{\partial t}\right) \vec{n}^{(0)} d s-\rho g\left(0,0, \xi_{3,9} A_{w}-\xi_{5,11} A_{w} X_{c . f}\right) \\
& \vec{M}^{(1)}=-\rho \int_{S_{A}+S_{B}}\left(\frac{\partial \phi^{(1)}}{\partial t}\right)\left(\vec{r} \times \vec{n}^{(0)}\right) d s-\rho g V\left(0, \xi_{4,10} \overline{G M_{T}}, \xi_{5,11} \overline{G M_{L}}\right)
\end{aligned}
$$

where $A_{w}$ is the water plane area, $X_{c . f}$ is the longitudinal center of flotation, $V$ is the displacement, $\overline{G M_{T}}$ is the transverse meta centric height, $\overline{G M_{L}}$ is the longitudinal meta centric height, respectively.

\section{$\underline{\text { Second-order Force }}$}

The mean second order force and moment can be written by the time average of equation (12), (13): 


$$
\begin{aligned}
\vec{F}^{(2)} & =\frac{1}{4} \rho g \oint_{L_{o}}\left|\tilde{\zeta}_{r}\right|^{2} \vec{n}_{2}^{(0)} d l \\
& -\frac{1}{4} \int_{S_{o}}\left|\nabla \tilde{\phi}^{(1)}\right|^{2} \vec{n}^{(0)} d s \\
& +\frac{1}{2} \operatorname{Re}\left[\tilde{R}_{1}^{*} \vec{F}^{(1)}\right] \\
& +\frac{1}{2} \rho \omega_{e} \int_{S_{o}} \operatorname{Im}\left[\vec{\alpha}^{*} \cdot \nabla \tilde{\phi}^{(1)}\right] \vec{n}^{(0)} d s \\
& +\frac{1}{2} \rho U \int_{S_{o}} \operatorname{Re}\left[\vec{\alpha}^{(1)^{*}} \cdot \nabla \tilde{\phi}_{x}^{(1)}\right] \vec{n}^{(0)} d s \\
& +\frac{1}{2} \rho g A_{w} X_{c . f} \operatorname{Re}\left[\tilde{\xi}_{4,10}^{*} \tilde{\xi}_{6,12}\right] \vec{k}^{(1)}
\end{aligned}
$$

where the superscript $\sim$ symbol denotes the complex amplitude of the variable, $*$ the complex conjugate and

$$
\vec{n}_{2}^{(0)}=\left(\vec{n}_{1}^{(0)}, \vec{n}_{2}^{(0)}, \vec{n}_{3}^{(0)}\right) / \sqrt{\vec{n}_{1}^{(0)^{2}}+\vec{n}_{2}^{(0)^{2}}}
$$

Similarly, the second order mean moment can be written:

$$
\begin{aligned}
\vec{M}^{(2)} & =\frac{1}{4} \rho g \oint_{L_{o}}\left|\tilde{\zeta}_{r}\right|^{2}\left(\vec{r} \times \vec{n}_{2}^{(0)}\right) d l \\
& -\frac{1}{4} \int_{S_{o}}\left|\nabla \tilde{\phi}^{(1)}\right|^{2}\left(\vec{r} \times \vec{n}^{(0)}\right) d s \\
& +\frac{1}{2} \operatorname{Re}\left[\tilde{R}_{1}^{*} \vec{M}^{(1)}\right] \\
& +\frac{1}{2} \rho \omega_{e} \int_{S_{o}} \operatorname{Im}\left[\vec{\alpha}^{*} \cdot \nabla \tilde{\phi}^{(1)}\right]\left(\vec{r} \times \vec{n}^{(0)}\right) d s \\
& +\frac{1}{2} \rho U \int_{S_{o}} \operatorname{Re}\left[\vec{\alpha}^{(1)^{*}} \cdot \nabla \tilde{\phi}_{x}^{(1)}\right]\left(\vec{r} \times \vec{n}^{(0)}\right) d s
\end{aligned}
$$

where $\vec{M}^{(1)}$ is the first order moment.

The motion-induced force is obtained by integration of radiation potential for the submerged body.

The motion induced force is 


$$
E_{i}=-i \rho \omega_{e} \iint_{S_{A}+S_{B}} \sum_{j=1}^{12} \xi_{j} \phi_{j} n_{i} d s=\sum_{j=1}^{12} T_{i j} \xi_{j} \quad \text { for } i=1,2, \ldots, 12
$$

where,

$$
T_{i j}=\omega_{e}^{2} A_{i j}-i \omega_{e} B_{i j}
$$

The terms $A_{i j}$ and $B_{i j}$ are added mass and damping coefficients, respectively.

$$
\begin{aligned}
& A_{i j}=\frac{\rho}{\omega_{e}} \operatorname{Im}\left[\iint_{S_{A}+S_{B}} \phi_{j} n_{i} d s\right] \\
& B_{i j}=\rho \operatorname{Re}\left[\iint_{S_{A}+S_{B}} \phi_{j} n_{i} d s\right]
\end{aligned}
$$

\section{Numerical Procedure}

The diffraction and radiation potential can be represented by the distribution with the density $\sigma(Q)$ on the surface SA and SB in the form.

$$
\iint_{S_{A}+S_{B}} \sigma(Q) G(P, Q) d s(Q)=4 \pi \phi(P) \text { for } P \text { inside fluid }
$$

where the Green's function $G(P, Q)$ is a source function at the field point $\mathrm{P}$ due to a unknown source density at the source point $\mathrm{Q}$. The unknown source density $\sigma(Q)$ can be found by imposing the body boundary conditions equation (6), (7) and (8) and it gives

$$
-\frac{1}{2} \sigma(P)+\frac{1}{4 \pi} \iint_{S_{A}+S_{B}} \sigma(Q) \frac{G(P, Q)}{\partial n} d s(Q)=V_{n} \text { for P body surface }
$$

where, $V_{n}$ is the normal component of the velocity on the body surface and is given in equation (6), (7) and (8). Due to the arbitrariness of the body surface and the complexity of the Green's function, equation (23) is solved numerically. The body surface SA and SB are replaced by a number of small $\mathrm{N}$ surface panels of area.

$$
-\frac{1}{2} \sigma_{i}+\frac{1}{4 \pi} \sum_{j=1, j \neq 1}^{N} \sigma_{j} A_{j} \frac{G\left(P_{i}, Q_{i}\right)}{\partial n}=V_{n i} \quad(\mathrm{i}=1,2, \ldots, \mathrm{N})
$$

In order to calculate the Green's function more efficiently, Telste and Noblesse [24]'s techniques have been used in this program.

\section{Equations of Motion for two floating bodies}

Under the assumption that the responses are linear and harmonic, the twelve linear coupled differential equations of motion for two floating bodies can be written in the following form 


$$
\sum_{j=1}^{12}\left[-\omega_{e}^{2}\left(M_{i j}+A_{i j}\right)-i \omega_{e} B_{i j}+C_{i j}\right] \xi_{j}=F_{i} \quad \text { for } \mathrm{i}=1,2, \ldots, 12
$$

where $M_{i j}$ is the generalized mass matrix for the ship A and ship B, $C_{i j}$ the restoring force matrix for ship A and ship B, respectively, $\xi_{j}$ the complex amplitude of the response motion in each of the six degree of freedom for each body, and $F_{i}$ the complex amplitude of the wave exciting force for ship A and ship B. The generalized mass matrix for two-body has the form of

$$
M_{i j}=\left[\begin{array}{cccccc}
M_{A} & 0 & 0 & 0 & M_{A} Z_{c A} & -M_{A} Y_{c A} \\
0 & M_{A} & 0 & -M_{A} Z_{c A} & 0 & M_{A} X_{c A} \\
0 & 0 & M_{A} & M_{A} Y_{c A} & -M_{A} X_{c A} & 0 \\
0 & -M_{A} Z_{c A} & M_{A} Y_{c A} & I_{44 A} & 0 & -I_{46 A} \\
M_{A} Z_{c A} & 0 & -M_{A} X_{c A} & 0 & I_{55} & 0 \\
-M_{A} Y_{c A} & M_{A} X_{C A} & 0 & -I_{64 A} & 0 & I_{66 A} \\
0 & 0 & 0 & 0 & 0 & 0 \\
0 & 0 & 0 & 0 & 0 & 0 \\
0 & 0 & 0 & 0 & 0 & 0 \\
0 & 0 & 0 & 0 & 0 & 0 \\
0 & 0 & 0 & 0 & 0 & 0 \\
0 & 0 & 0 & 0 & 0 & 0
\end{array}\right.
$$
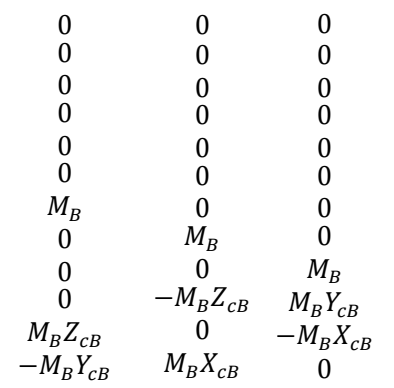

$$
\left.\begin{array}{ccc}
0 & 0 & 0 \\
0 & 0 & 0 \\
0 & 0 & 0 \\
0 & 0 & 0 \\
0 & 0 & 0 \\
0 & 0 & 0 \\
0 & M_{B} Z_{C B} & -M_{B} Y_{C B} \\
-M_{B} Z_{C B} & 0 & M_{B} X_{C B} \\
M_{B} Y_{C B} & -M_{B} X_{C B} & 0 \\
I_{1010 B} & 0 & -I_{1012 B} \\
0 & I_{111 B} & 0 \\
-I_{1210 B} & 0 & I_{1212 B}
\end{array}\right]
$$

$$
\begin{array}{lll}
X_{c A}=X_{g A}-X_{m A}, & Y_{c A}=Y_{g A}-Y_{m A}, & Z_{c A}=Z_{g A}-Z_{m A} \\
X_{c B}=X_{g B}-X_{m B}, & Y_{c B}=Y_{g B}-Y_{m B}, & Z_{c B}=Z_{g B}-Z_{m B}
\end{array}
$$

where $M_{A}, M_{B}$ are the masses, $I_{i i}$, $I_{i i}$ the moments of inertia in i-th modes and, $I_{i j}$, $I_{i j B}$ the products of inertia, $\left(X_{g}, Y_{g}, Z_{g}\right)$ the center of gravity, $\left(X_{m}, Y_{m}, Z_{m}\right)$ the center of motion of the ship A and ship B, respectively.

The added mass and damping coefficients matrices are represented by including fully coupled effects for ship A and ship B even they have one longitudinal plane of symmetry.

$$
\begin{array}{ll}
A_{i j}=B_{i j} \neq 0 & \text { for } i=2,4,6,8,10,12 \text { and } j=1,3,5,7,9,11 \\
A_{i j}=B_{i j} \neq 0 & \text { for } j=1,3,5,7,9,11 \text { and } i=2,4,6,8,10,12
\end{array}
$$

Furthermore, for a two-body in the free surface the linear hydrostatic restoring force coefficients matrices are uncoupled while the added mass and damping matrices are coupled;

$$
\begin{aligned}
& C_{33}=\rho g A_{w A}, C_{99}=\rho g A_{w B} \\
& C_{44}=\rho g V_{A} \overline{G M_{T A}}, C_{1010}=\rho g V_{B} \overline{G M_{T B}} \\
& C_{55}=\rho g V_{A} \overline{G M_{L A}}, C_{1111}=\rho g V_{B} \overline{G M_{L B}} \\
& C_{35}=C_{53}=-\rho g M_{w A}, C_{911}=C_{119}=-\rho g M_{w B}
\end{aligned}
$$

where $A_{w A}, A_{w B}$ are the water plane area, $M_{w A}, M_{w B}$ the moment of the water plane, $V_{A}$, $V_{B}$ the displacement, $\overline{G M_{T A}}, \overline{G M_{T B}}$ the transverse meta centric height, $\overline{G M_{L A}}, \overline{G M_{L B}}$ the longitudinal meta centric height for ship A and ship B, respectively. 


\section{Relative motion between two floating bodies}

The longitudinal, horizontal and vertical relative motion between ship A and ship B at any position can be expressed as three components by Fang and Kim [5],

$$
\begin{aligned}
& \frac{L_{R}}{S_{a}}=\frac{1}{S_{a}}\left[\left(\xi_{1}+z_{A} \xi_{5}-y_{A} \xi_{6}\right)-\left(\xi_{7}+z_{B} \xi_{11}-y_{B} \xi_{12}\right)\right] \\
& \frac{H_{R}}{S_{a}}=\frac{1}{S_{a}}\left[\left(\xi_{2}+x_{A} \xi_{6}-z_{A} \xi_{4}\right)-\left(\xi_{8}+x_{B} \xi_{12}+z_{B} \xi_{10}\right)\right] \\
& \frac{V_{R}}{S_{a}}=\frac{1}{S_{a}}\left[\left(\xi_{3}-x_{A} \xi_{5}+y_{A} \xi_{4}\right)-\left(\xi_{9}-x_{B} \xi_{11}+y_{B} \xi_{10}\right)\right]
\end{aligned}
$$

where, $\left(x_{A}, y_{A}, z_{A}\right)$ and $\left(x_{B}, y_{B}, z_{B}\right)$ are the coordinates of the position with respect to each body frame system; see Fig. 1 .

\section{Wave induced structural loads for two floating bodies}

The wave induced structural loads, such as shear forces and bending moment between two floating bodies in waves at a particular cross section arise from the difference between the mass inertia forces and the sum of wave induced external forces acting on the portion of the hull forward of the section in question of 2-dimensional strip theory by Salvesen et al [25] and 3-dimensional theory by Chan [26]. The ship can be considered rigid body in the determination of the wave loads. The mass inertia forces are due to the accelerations of the each ship while wave induced external forces are due to the static restoring forces, the wave exciting forces as well as the motion induced hydrodynamic forces.

The wave loads between two floating bodies consist of the compression force $F_{1}, F_{7}$, the horizontal shear force $F_{2}, F_{8}$, and the vertical shear force $F_{3}, F_{9}$, the torsional moment $F_{4}, F_{10}$, the vertical bending moment $F_{5}, F_{11}$, and the horizontal bending moment $F_{6}, F_{12}$ for ship A and ship B, respectively.

$$
\begin{array}{lll}
F_{A}=F_{1} \vec{\imath}+F_{2} \vec{\jmath}+F_{3} \vec{k}, & M_{A}=F_{4} \vec{\imath}+F_{5} \vec{\jmath}+F_{6} \vec{k} & \text { for ship A } \\
F_{B}=F_{7} \vec{\imath}+F_{8} \vec{\jmath}+F_{9} \vec{k}, \quad M_{B}=F_{10} \vec{\imath}+F_{11} \vec{\jmath}+F_{12} \vec{k} & \text { for ship B }
\end{array}
$$

The definition of sign conventions for wave induced structural loads are presented in Fig. 2 and expressed in the form including speed terms as follows, 
Mun Sung Kim, Kwang Hyo Jung Sung Boo Park
Wave Induced Coupled Motions and Structural Loads between Two Offshore Floating Structures in Waves
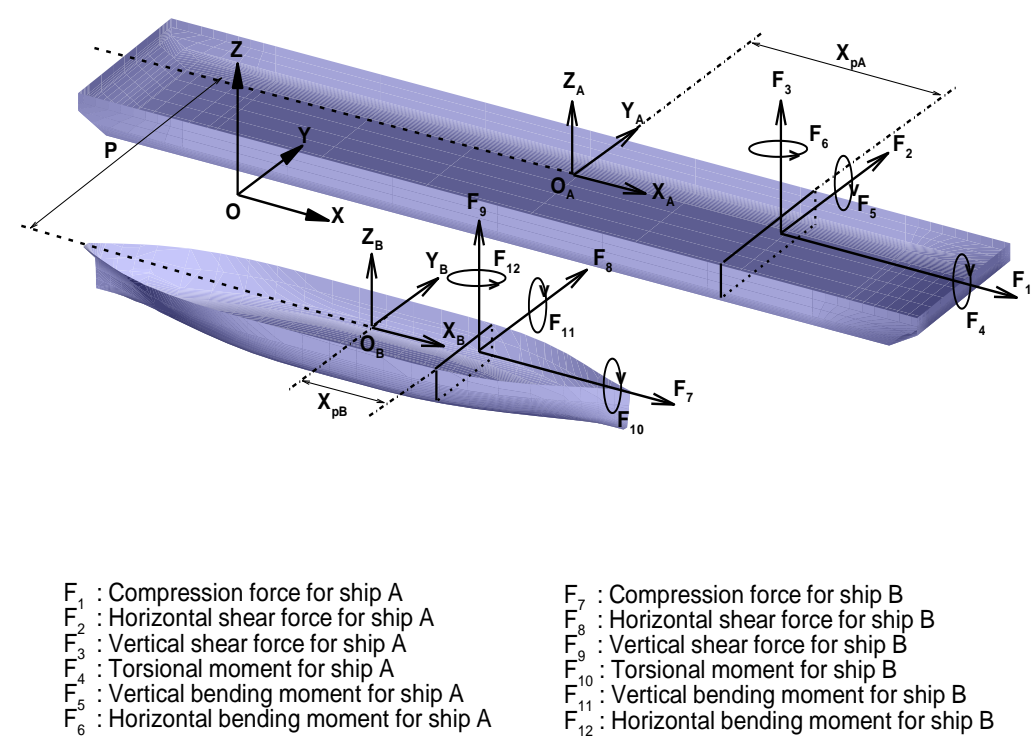

Fig. 2. Definition of sign conventions for wave induced structural loads

$$
\begin{aligned}
F_{1}= & \int m_{A}\left(\ddot{\xi}_{1}+z_{g A} \ddot{\xi}_{5}\right) d x_{A}-\rho \iint\left(\phi_{t}-U \phi_{x}\right) n_{1} d s_{A} \\
F_{2}= & \int m_{A}\left(\ddot{\xi}_{2}+x_{A} \ddot{\xi}_{6}-z_{g A} \ddot{\xi}_{4}\right) d x_{A}-\rho \iint\left(\phi_{t}-U \phi_{x}\right) n_{2} d s_{A} \\
F_{3}= & \int m_{A}\left(\ddot{\xi}_{3}+x_{A} \ddot{\xi}_{5}\right) d x_{A}-\rho \iint\left(\phi_{t}-U \phi_{x}\right) n_{3} d s_{A} \\
& +2 \rho g \int y_{A}\left(\xi_{3}-x_{A} \xi_{5}\right) d x_{A} \\
F_{4}= & \int\left[i_{44} \ddot{\xi}_{4}-m_{A} z_{g A}\left(\ddot{\xi}_{2}+x_{A} \ddot{\xi}_{6}\right)\right] d x_{A}-\rho \iint\left(\phi_{t}-U \phi_{x}\right) n_{4} d s_{A} \\
& +\rho \xi_{4}\left[2 \rho \int y_{A}^{3} d x_{A}-\int m_{A} z_{g A} d x_{A}+\rho \int A_{A} z_{b A} d x_{A}\right] \\
F_{5}= & -\left(x_{A}-x_{p A}\right) F_{3} \\
F_{6}= & \left(x_{A}-x_{p A}\right) F_{2} \\
F_{7}= & \int m_{B}\left(\ddot{\xi}_{7}+z_{g B} \ddot{\xi}_{11}\right) d x_{B}-\rho \iint\left(\phi_{t}-U \phi_{x}\right) n_{7} d s_{B} \\
F_{8}= & \int m_{B}\left(\ddot{\xi}_{8}+x_{B} \ddot{\xi}_{12}-z_{g B} \ddot{\xi}_{10}\right) d x_{B}-\rho \iint\left(\phi_{t}-U \phi_{x}\right) n_{8} d s_{B} \\
F_{9}= & \int m_{B}\left(\ddot{\xi}_{9}+x_{B} \ddot{\xi}_{11}\right) d x_{B}-\rho \iint\left(\phi_{t}-U \phi_{x}\right) n_{9} d s_{B}
\end{aligned}
$$




$$
\begin{aligned}
& +2 \rho g \int y_{B}\left(\xi_{9}-x_{B} \xi_{11}\right) d x_{B} \\
F_{10}= & \int\left[i_{1010} \ddot{\xi}_{10}-m_{B} z_{g B}\left(\ddot{\xi}_{8}+x_{B} \ddot{\xi}_{12}\right)\right] d x_{B}-\rho \iint\left(\phi_{t}-U \phi_{x}\right) n_{10} d s_{B} \\
& +g \xi_{10}\left[2 \rho \int y_{B}^{3} d x_{B}-\int m_{B} z_{g B} d x_{B}+\rho \int A_{B} z_{b B} d x_{B}\right] \\
F_{11}= & -\left(x_{B}-x_{p B}\right) F_{9} \\
F_{12}= & \left(x_{B}-x_{p B}\right) F_{8}
\end{aligned}
$$

where $m_{A}, m_{B}$ are the sectional mass per unit length of the ship, $z_{g A}, z_{g B}$ the vertical position of center of gravity of the sectional mass, $z_{b A}, z_{b B}$ the vertical position of center of submerged cross section, $A_{A}, A_{B}$ the area of the submerged cross section, $i_{44}, i_{1010}$ the sectional mass moment of inertia about the $\mathrm{x}$-axis. The $\int$ and $\iint$ are the surface integration over the mean wetted hull surface forward of specific cross section and the line integration along the hull forward of specific section, respectively.

\section{Numerical Results and Discussion}

The Numerical calculations of hydrodynamic pressure, wave exciting force, motion response, relative motion and wave loads between two floating structures have been carried out for Kodan [2]'s rectangular barge and conventional ship model with zero speed. The principal particulars of a barge and a ship model are given in Table 1. The distance between barge and ship from each body's center of gravity is $1.2 \mathrm{~m}$, i.e., $\mathrm{P}=1.2 \mathrm{~m}$ (see Fig.3). The longitudinal centers of barge and ship are positioned same.

In order to validate the developed motion prediction program, the comparisons are performed for Kodan [2]'s experimental and 2-D strip theory numerical results, Fang and Kim [5]'s 2-D strip theory numerical results and Fang and Chen [6, 27]'s 3-D potential theory numerical results, respectively.

The numerical calculated results of hydrodynamic pressure distribution, wave exciting force, motion response, relative motion and wave loads in waves are presented in Fig. 5 through Fig. 22.

Table 1. Principal particulars of two models (Kodan, [2])

\begin{tabular}{|c|c|c|c|}
\hline Items & Unit & Barge(Left) & Ship(Right) \\
\hline Length & $\mathrm{m}$ & 3.125 & 2.088 \\
\hline Breadth & $\mathrm{m}$ & 0.600 & 0.369 \\
\hline Draft & $\mathrm{m}$ & 0.113 & 0.131 \\
\hline Displacement & $\mathrm{m}^{3}$ & 0.203 & 0.081 \\
\hline Water plane area & $\mathrm{m}^{2}$ & 1.875 & 0.685 \\
\hline $\mathrm{GM}_{\mathrm{T}}$ & $\mathrm{m}$ & 0.223 & 0.074 \\
\hline $\mathrm{GM}_{\mathrm{L}}$ & $\mathrm{m}$ & 7.184 & 2.523 \\
\hline $\mathrm{KG}$ & $\mathrm{m}$ & 0.106 & 0.080 \\
\hline $\mathrm{K}_{\mathrm{xx}}$ & $\mathrm{m}$ & 0.118 & 0.097 \\
\hline $\mathrm{K}_{\mathrm{yy}}$ & $\mathrm{m}$ & 0.751 & 0.506 \\
\hline
\end{tabular}




\begin{tabular}{|c|c|c|c|}
\hline $\mathrm{K}_{z z}$ & $\mathrm{~m}$ & 0.760 & 0.480 \\
\hline
\end{tabular}

The distance between the centers of two models, $\mathrm{P}=1.2 \mathrm{~m}$

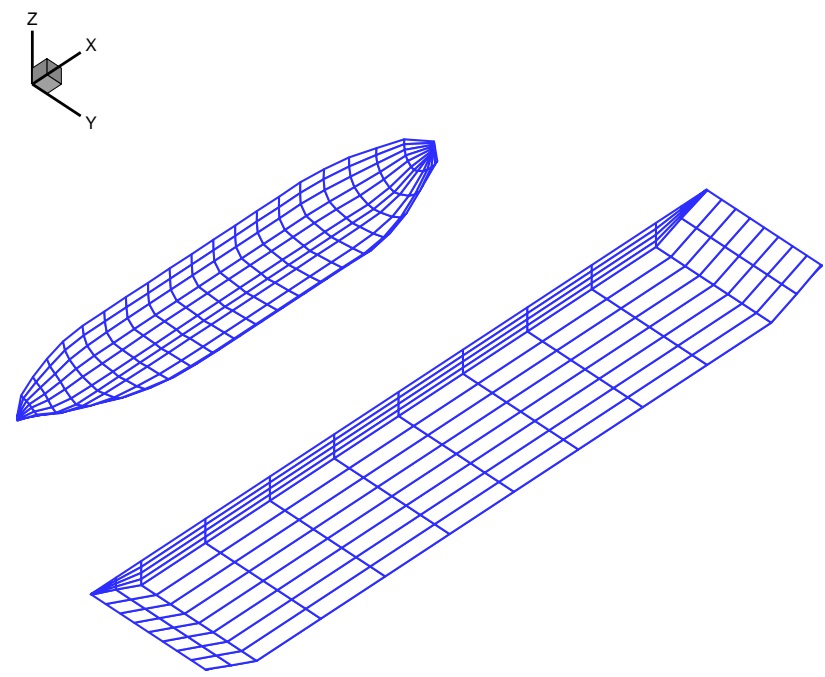

Fig 3. Panel Arrangement for barge and side positioned ship (fish-eye view)

The calculations of second order wave drift force between two floating structures have been carried out for same size barge model. The principal particulars of barge are presented in Table 2. The distance between two barges, from the wall of each barge, are $10.0 \mathrm{~m}$ for side-byside offloading arrangement (see Fig. 4).

The comparisons are performed to validate the program for Pinkster [20]'s experimental results. The numerical results of motion response and drift forces are presented in Fig. 23 through Fig. 25.

Table 2. Principal particulars of two barge models (Pinkster, [20])

\begin{tabular}{|c|c|c|c|}
\hline Items & Unit & A Barge (Left) & B Barge (Right) \\
\hline Length & $\mathrm{m}$ & 150.0 & 150.0 \\
\hline Breadth & $\mathrm{m}$ & 50.0 & 50.0 \\
\hline Draft & $\mathrm{m}$ & 10.0 & 10.0 \\
\hline Displacement & $\mathrm{m}^{3}$ & 73,750 & 73,750 \\
\hline Water plane area & $\mathrm{m}^{2}$ & 7,500 & 7,500 \\
\hline $\mathrm{GM}_{\mathrm{T}}$ & $\mathrm{m}$ & 16.23 & 16.23 \\
\hline $\mathrm{GM}_{\mathrm{L}}$ & $\mathrm{m}$ & 186.0 & 186.0 \\
\hline KG & $\mathrm{m}$ & 10.0 & 10.0 \\
\hline
\end{tabular}

The distance between the centers of two models, $\mathrm{P}=10.0 \mathrm{~m}$ 


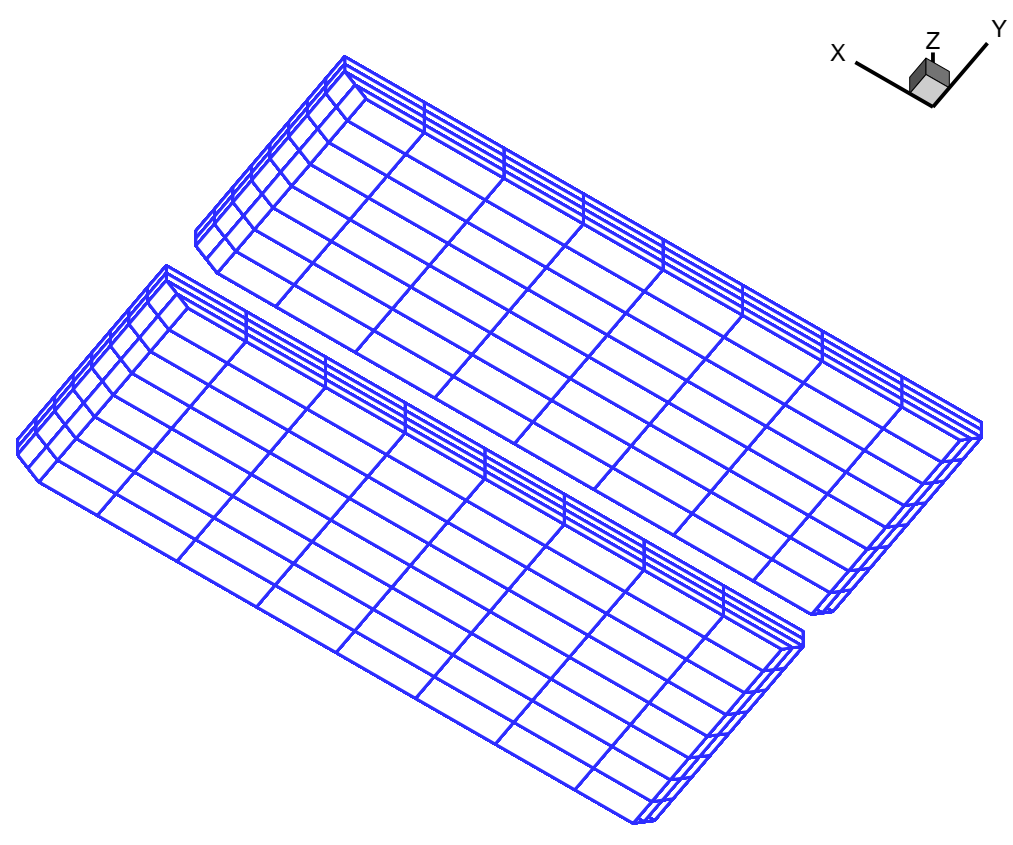

Fig. 4. Panel Arrangement of two barges for Side-by-Side offloading (fish-eye view)

\subsection{Hydrodynamic pressure distribution between barge and ship}

The hydrodynamic pressure distributions on the ship hull surface with and without barge are shown in Fig. 5 through Fig. 7. The hydrodynamic pressure is non-dimensionalized by the density of sea water, gravitational constant, wave amplitude.

Fig. 5 shows the hydrodynamic pressure distribution for ship with and without barge in following seas $\left(\beta=0^{\circ}\right)$ which wavelength is $2.038 \mathrm{~m}$ and has same length as ship length. In case of ship floating alone without barge, the hydrodynamic pressure distribution has symmetric behavior along the x-direction, so there is no any horizontal mode force and motion. However, in case of ship with barge, the hydrodynamic pressure has asymmetric behavior along the $\mathrm{x}$ direction due to hydrodynamic interaction, so it is expected that the horizontal mode force and motion in following and head seas. Fig. 6 and 7 show the hydrodynamic pressure distributions on the ship at $45^{\circ}$ and $-45^{\circ}$ heading waves. If the ship is floating alone, there is no hydrodynamic pressure difference irrelevant to wave heading angle. However, in case of ship with barge, the hydrodynamic pressure has under the influence of the barge. The hydrodynamic pressure of the ship with barge is smaller on the leeside than on the weather side due to the hydrodynamic interaction by the sheltering effect. 
Mun Sung Kim, Kwang Hyo Jung Sung Boo Park
Wave Induced Coupled Motions and Structural Loads between Two Offshore Floating Structures in Waves
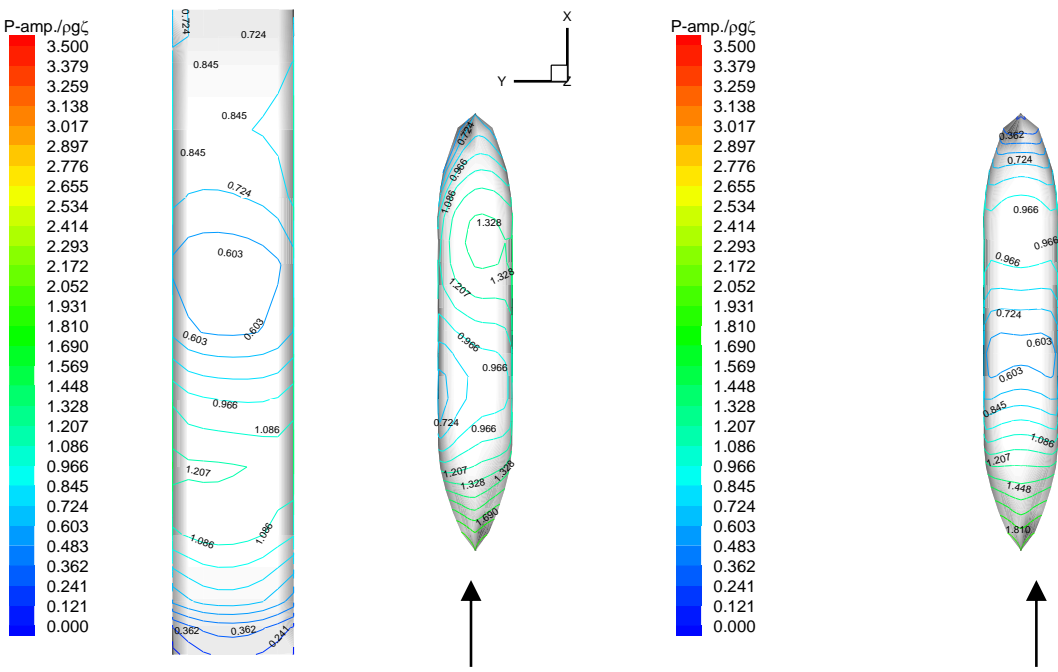

Fig. 5. Hydrodynamic pressure for ship with and without barge at $\beta=0^{\circ}(\lambda=2.038 \mathrm{~m})$
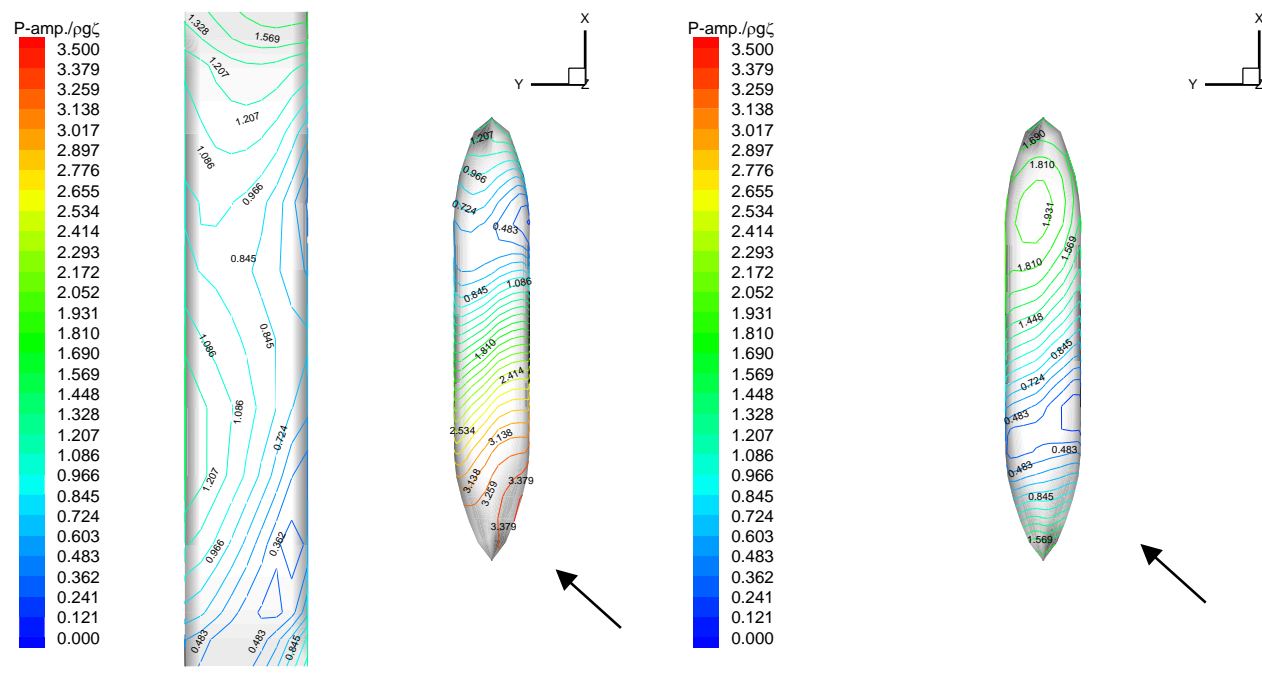

Fig. 6. Hydrodynamic pressure for ship with and without barge at $\beta=45^{\circ}(\lambda=2.038 \mathrm{~m})$
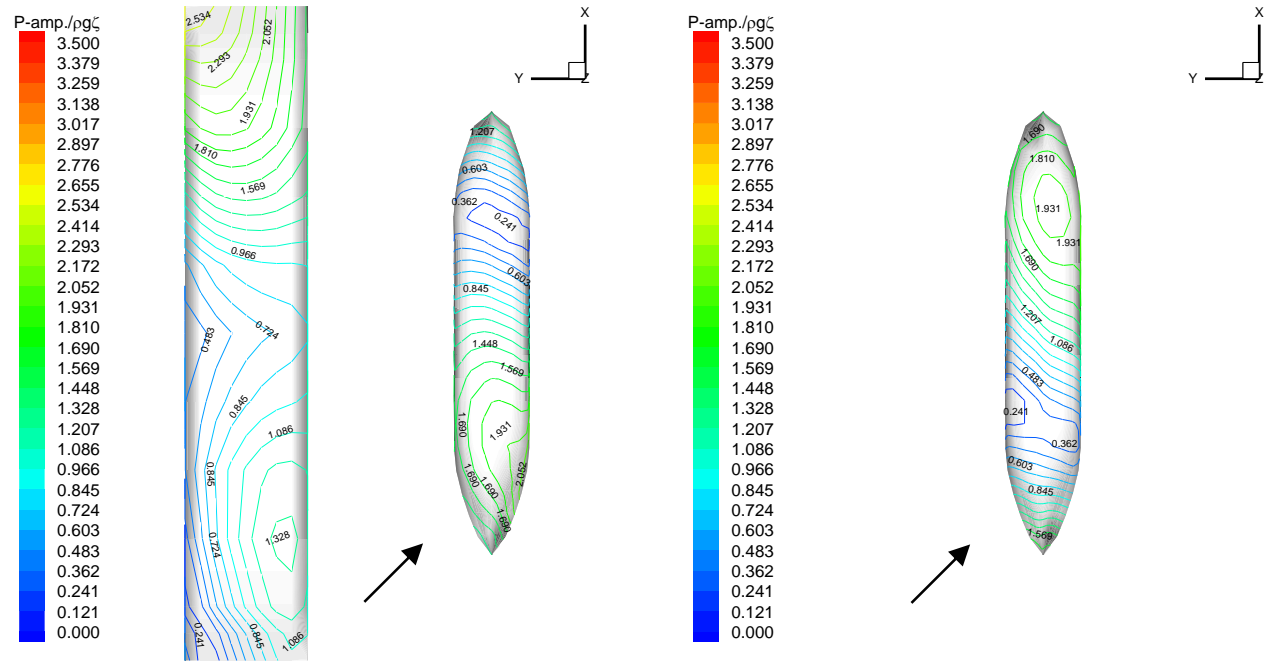

Fig. 7. Hydrodynamic pressure for ship with and without barge at $\beta=-45^{\circ}(\lambda=2.038 \mathrm{~m})$ 


\subsection{Wave exciting force and moment between barge and ship}

The wave exciting forces and moments are shown in Fig. 8 through Fig. 10. The dashed line shows the results of the ship without barge. Fig. 8 and 9 show the sway and heave exciting force for ship at $45^{\circ}$ and $-45^{\circ}$ heading waves. The roll exciting moment for a ship at $45^{\circ}$ and $45^{\circ}$ heading waves are shown in Fig. 10.

Fig. 11 show the sway and heave exciting force for ship at $0^{\circ}$ heading waves. Due to the hydrodynamic interaction effect between barge and ship, the ship exciting forces and moments with barge are quite different from the exciting forces and moments of a single ship without barge. The one of the interesting phenomena on two-body wave exciting forces that the interaction effect was found in following sea $\left(\beta=0^{\circ}\right)$, where no sway exciting forces occur if the ship was floating alone. Generally, theoretical results give a good correlation with the Kodan [2]'s experimental results except the roll exciting moment at $\beta=-45^{\circ}$.
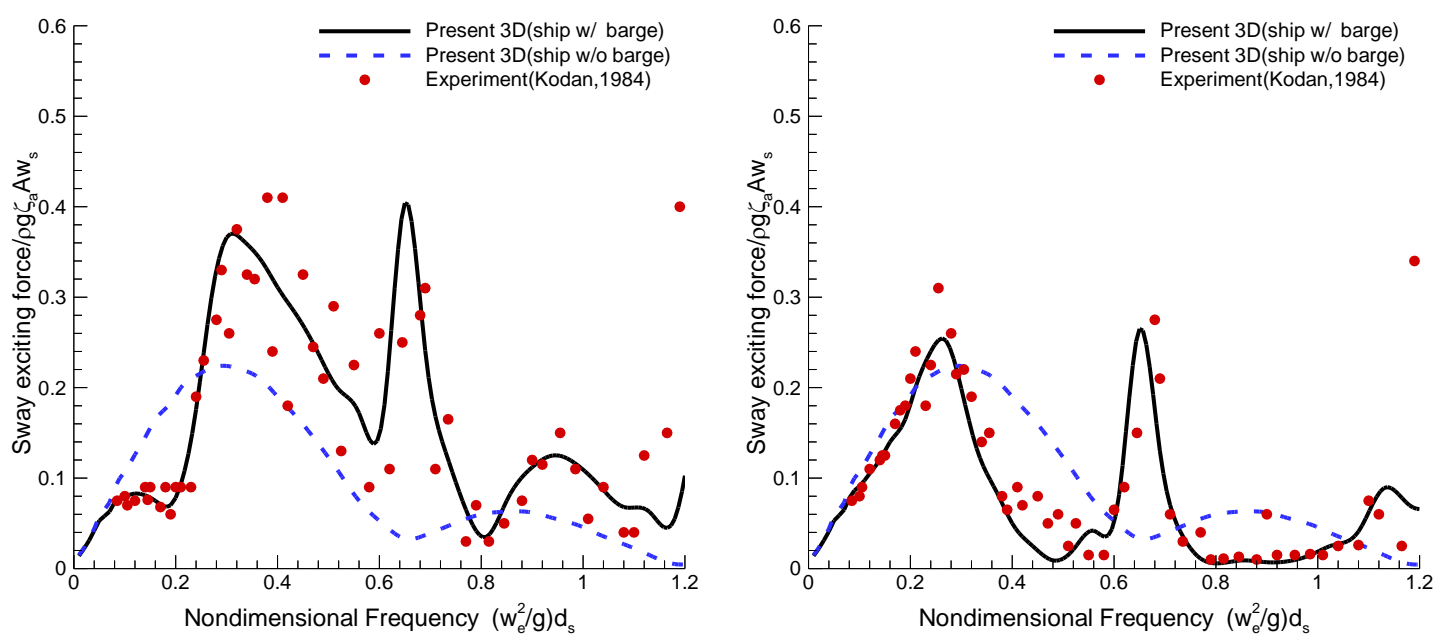

Fig. 8. Sway exciting force for ship with and without barge at $\beta=45^{\circ}, \beta=-45^{\circ}$
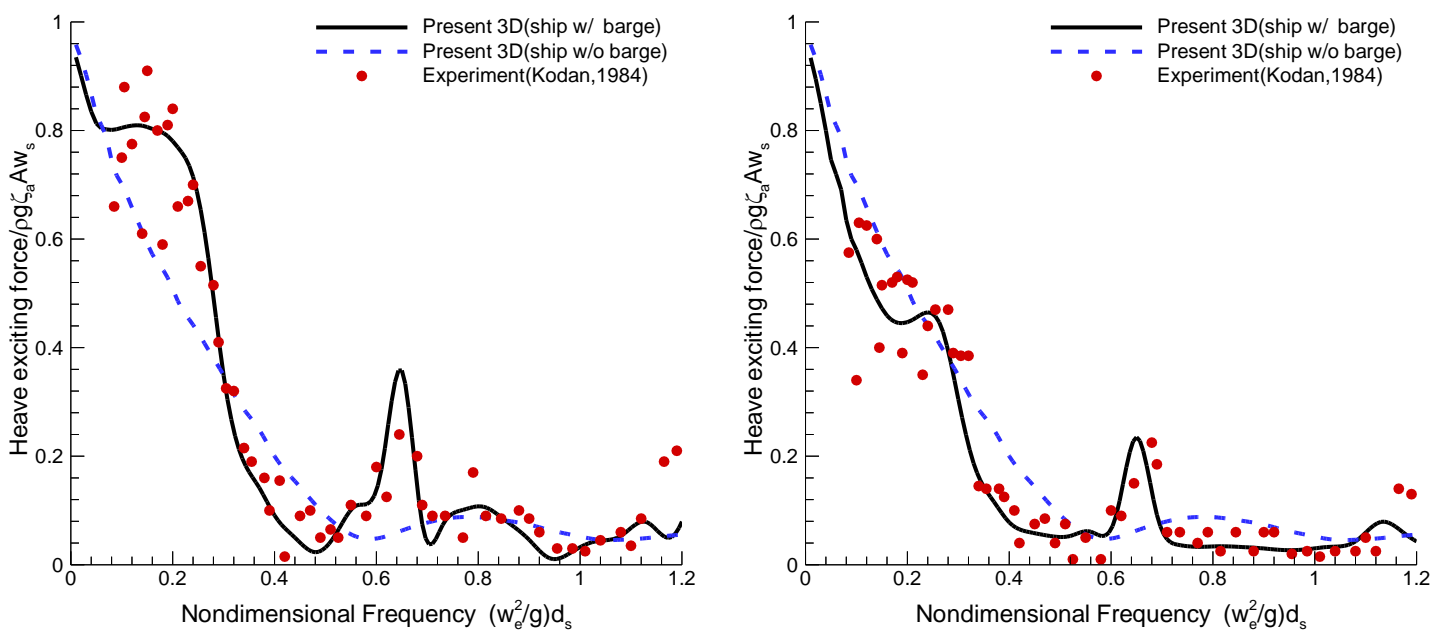

Fig. 9. Heave exciting force for ship with and without barge at $\beta=45^{\circ}, \beta=-45^{\circ}$ 
Mun Sung Kim, Kwang Hyo Jung Sung Boo Park
Wave Induced Coupled Motions and Structural Loads between Two Offshore Floating Structures in Waves
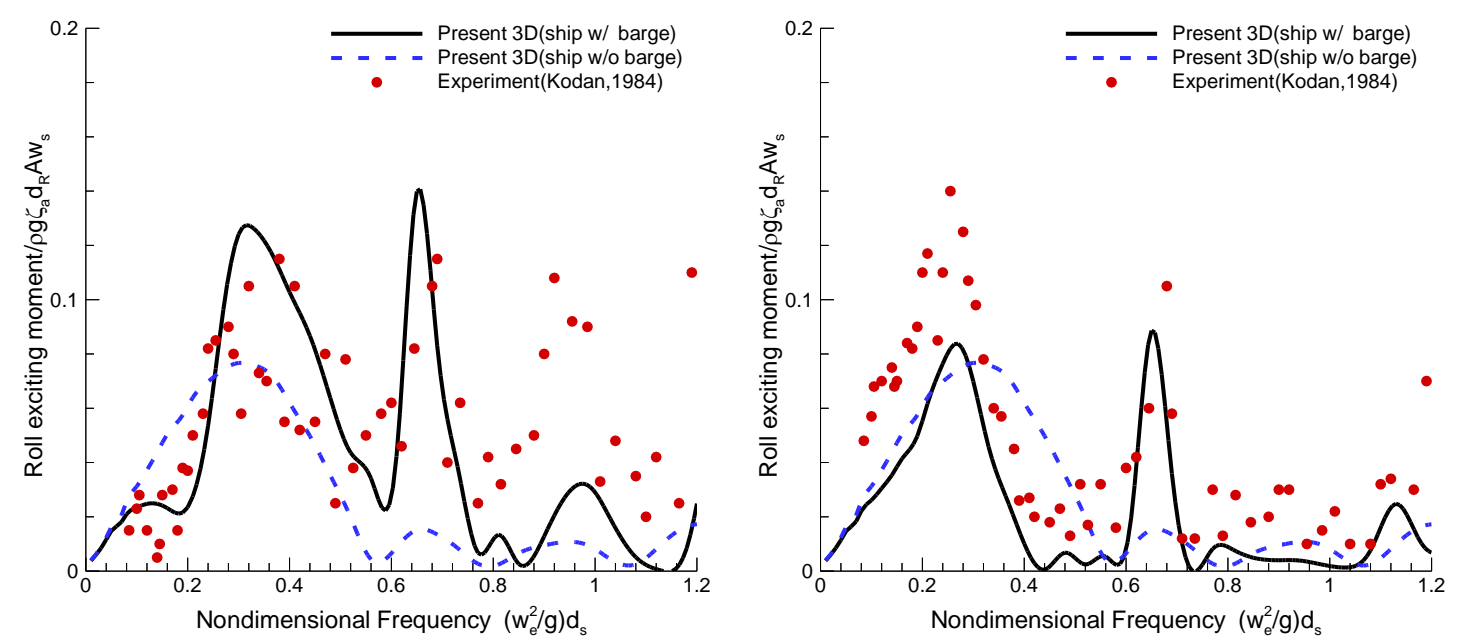

Fig. 10. Roll exciting moment for ship with and without barge at $\beta=45^{\circ}, \beta=-45^{\circ}$
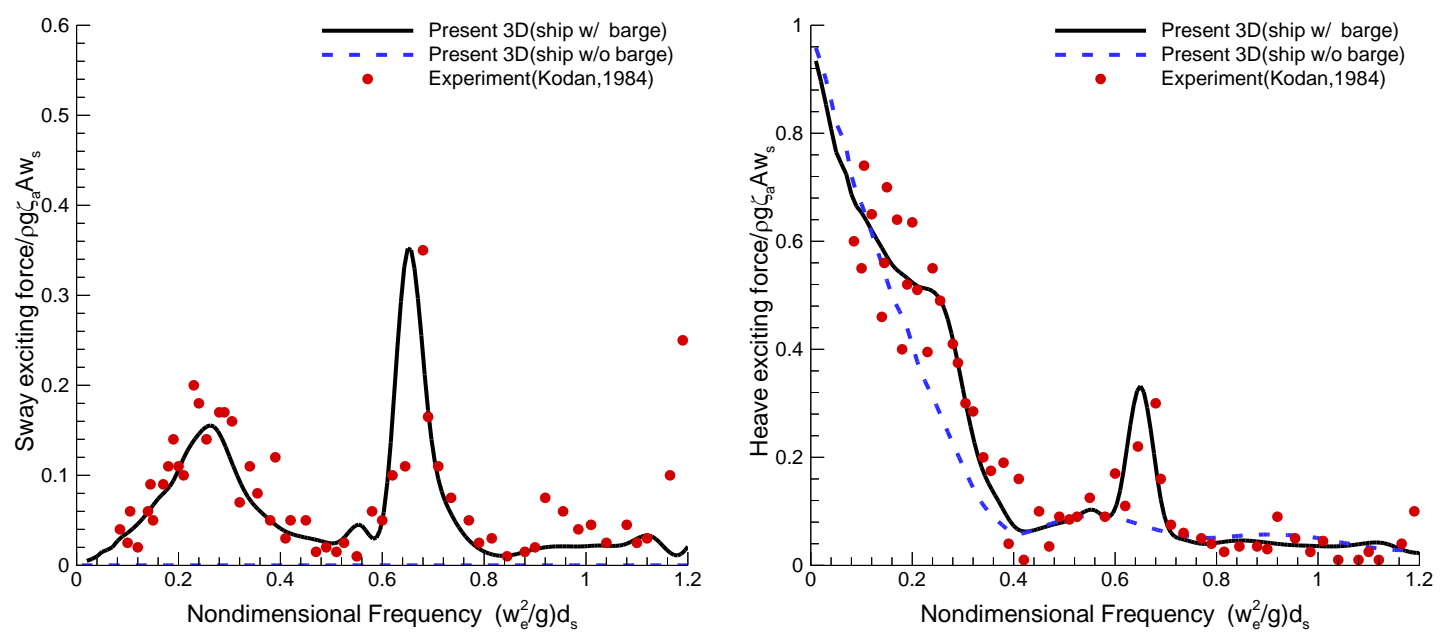

Fig. 11. Sway and Heave exciting force for ship with and without barge at $\beta=0^{\circ}$ 


\subsection{Motion behaviors between barge and ship}

Fig. 12 show the sway amplitudes for ship at $45^{\circ}$ and $-45^{\circ}$ heading waves. The heave amplitudes for a ship at $45^{\circ}$ and $-45^{\circ}$ heading waves are shown in Fig. 13. Due to the hydrodynamic interaction effect between barge and ship, the coupled resonance occur in the motion responses and the ship motion responses with barge are quite different from the responses of a single ship without barge. All the motion responses of the ship with barge are smaller on the leeside than on the weather side because of the sheltering effect.

Fig. 14 show the sway and the heave amplitudes for barge at $45^{\circ}$ and $-45^{\circ}$ heading waves, respectively. Unlike the ship's case, the motion responses of barge with ship are the same as the motion responses of single barge without ship except several frequencies, which causes the hydrodynamic interaction effect between barge and ship. In general, the present 3-D results are much closer to the experimental result than other numerical results specially heave and sway motion response.
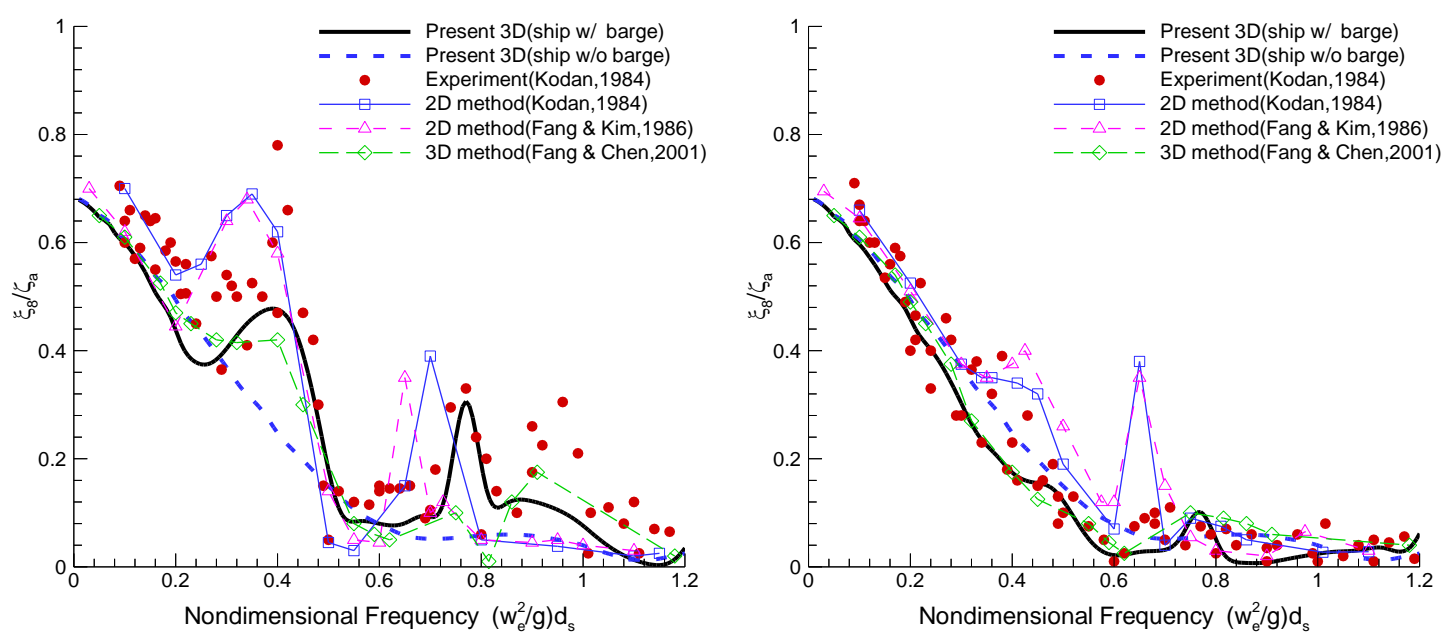

Fig. 12. Sway amplitude for ship with and without barge at $\beta=45^{\circ}, \beta=-45^{\circ}$
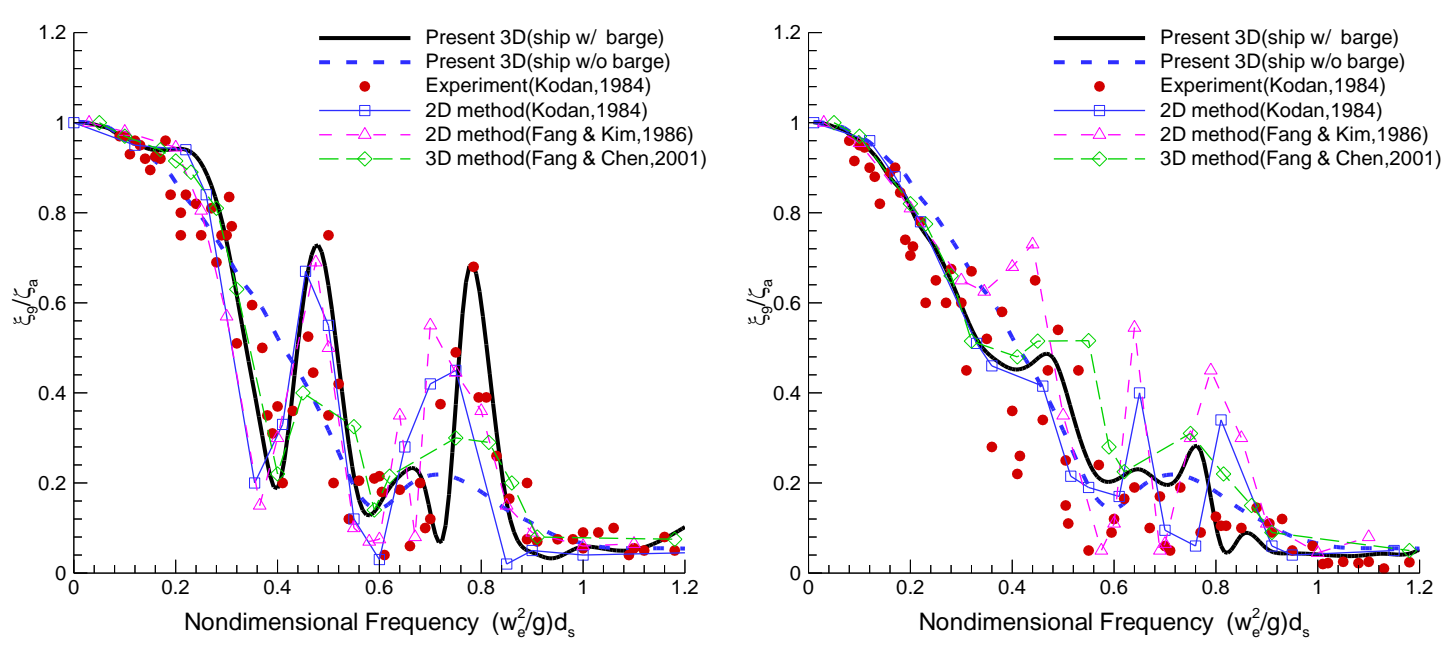

Fig. 13. Heave amplitude for ship with and without barge at $\beta=45^{\circ}, \beta=-45^{\circ}$ 

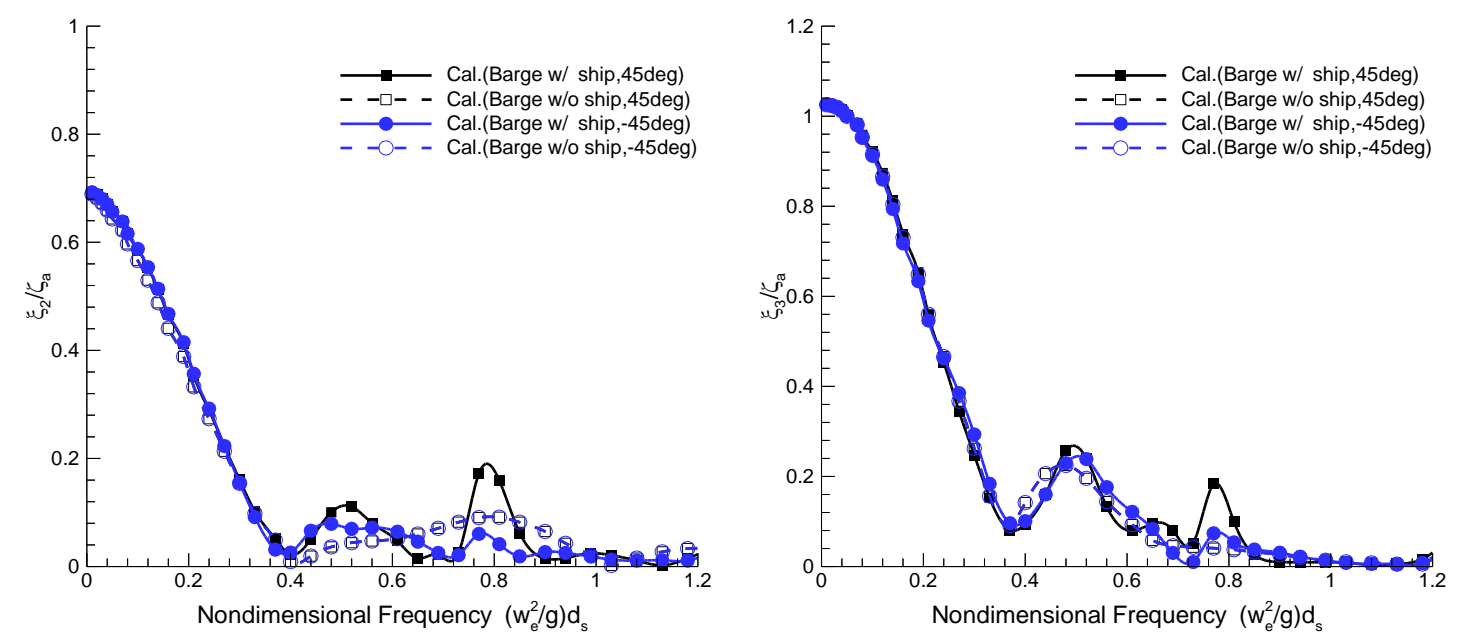

Fig. 14. Sway and Heave amplitude for barge with and without ship at $\beta=45^{\circ}, \beta=-45^{\circ}$

\subsection{Relative motions between barge and ship}

Fig. 15 shows the horizontal relative motion amplitudes at $45^{\circ}$ and $-45^{\circ}$ heading waves. The calculation positions for the relative motion are each body's center of gravity, i.e., $\left(\mathrm{x}_{\mathrm{A}}, \mathrm{y}_{\mathrm{A}}\right.$, $\left.\mathrm{z}_{\mathrm{A}}\right)=(0,0,0),\left(\mathrm{x}_{\mathrm{B}}, \mathrm{y}_{\mathrm{B}}, \mathrm{z}_{\mathrm{B}}\right)=(0,0,0)$.

Fig. 16 shows the vertical relative motion amplitude at $45^{\circ}$ and $-45^{\circ}$ heading waves. For comparison of the present 3-D relative motion results, Fang and Kim [5]'s 2-D results and Fang and Chen [6]'s 3-D results are used. Generally, the large relative motions between two bodies occur around low frequency region and coupled resonance frequency region. As we can see, the present 3-D results have the same behavior as Fang and Chen [6]'s 3-D results except the high frequency, which caused the difference of heave motion responses in coupled resonance regions. Like the hydrodynamic pressure, wave exciting force and motion responses, all the relative motion responses of the ship with barge are smaller on the leeside than on the weather side due to the sheltering effect.
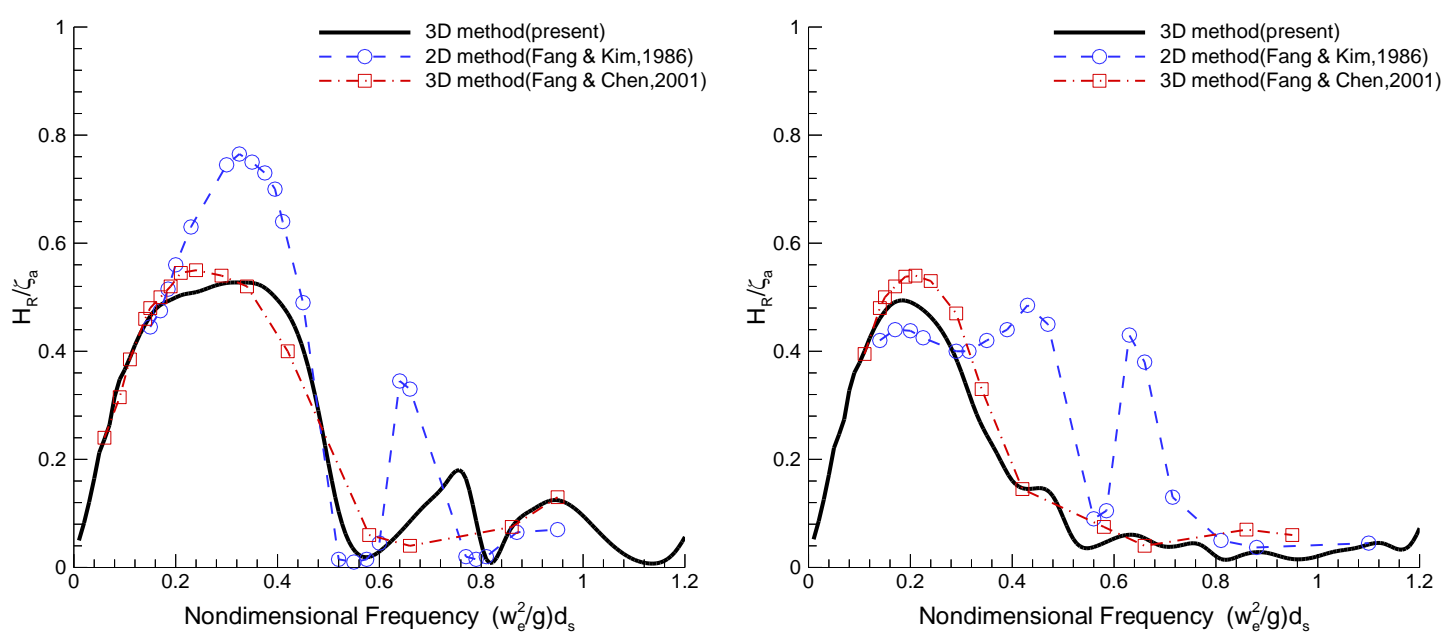

Fig. 15. Horizontal relative motion between barge and ship at $\beta=45^{\circ}, \beta=-45^{\circ}$ 

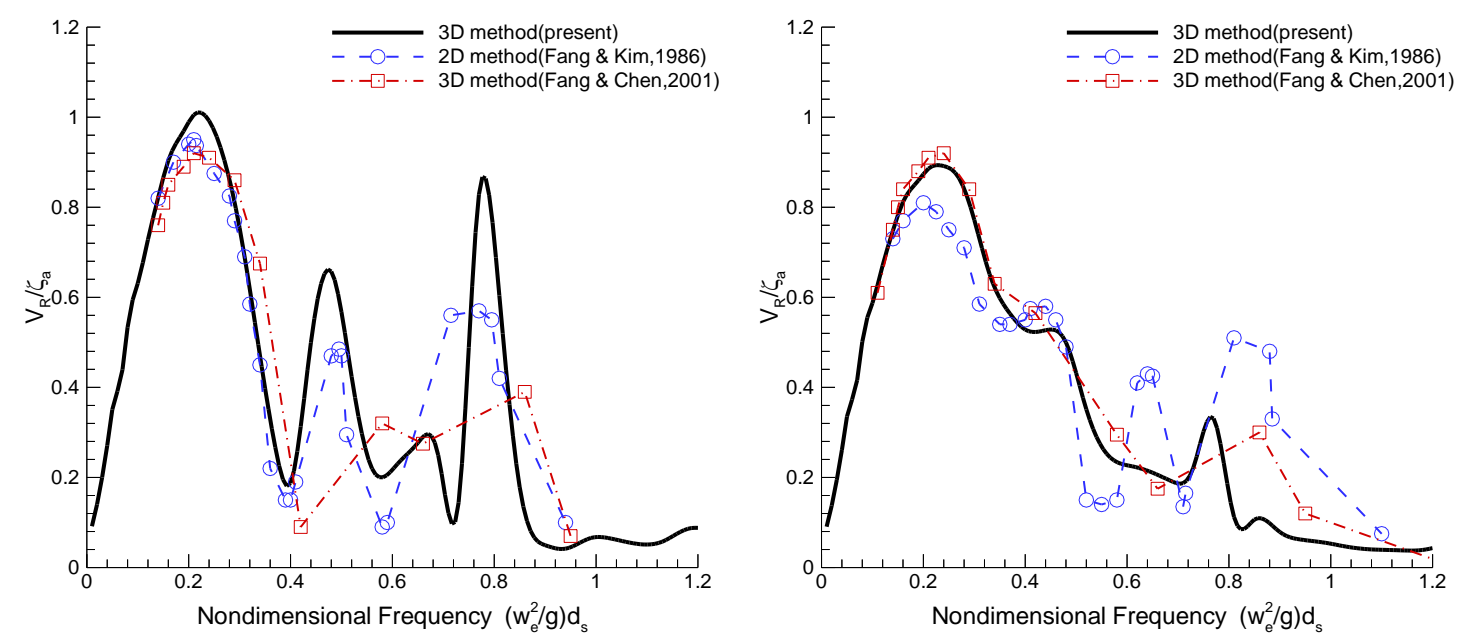

Fig. 16. Vertical relative motion between barge and ship at $\beta=45^{\circ}, \beta=-45^{\circ}$

\subsection{Wave induced structural loads between barge and ship}

Once we know the wave exciting force and the motion responses between two bodies, we can predict the wave induced structural loads at mid-ship section of the ship by using equation (35) through (46). The wave loads for ship at mid-ship section are shown in Fig. 17 through Fig. 22. Horizontal bending moments for ship with and without barge at $45^{\circ}$ and $-45^{\circ}$ heading waves are shown in Fig. 17, Fig. 18 and Fig. 19 show the vertical bending moments and torsional moments at $45^{\circ}$ and $-45^{\circ}$ heading waves, respectively. Unfortunately, the experimental data was not available to compare for the calculated wave loads. However, it is a reasonable result that because of the equation of wave loads can be solved numerically by known wave exciting force and motion responses for correspond wave frequency and heading angle.

Like the hydrodynamic pressure distributions, wave exciting forces and motion responses, the hydrodynamic interaction effects between two bodies are also more affect the wave loads of ship with barge than that of ship floating alone without barge, specially resonance frequency region. Due to the sheltering effect, the wave loads on the lee side are generally smaller than the case on the weather side. As shown in Fig. 20 through Fig. 22, the one of the interesting phenomena on two-body wave loads that the interaction effect was found in head and following sea $\left(\beta=180^{\circ}, \beta=0^{\circ}\right)$, where no horizontal bending moment and torsional moment occur if the ship was floating alone. 
Mun Sung Kim, Kwang Hyo Jung Sung Boo Park
Wave Induced Coupled Motions and Structural Loads between Two Offshore Floating Structures in Waves
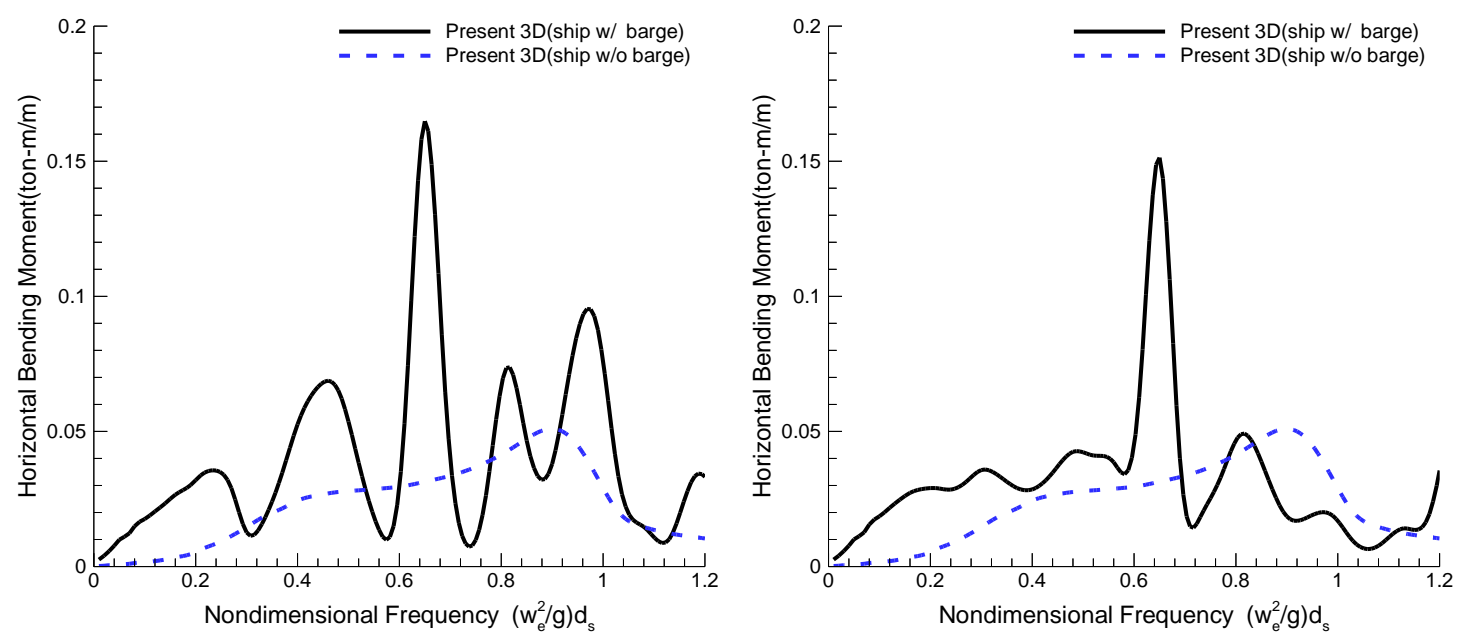

Fig. 17. Horizontal Bending Moment for ship with and without barge at $\beta=45^{\circ}, \beta=-45^{\circ}$
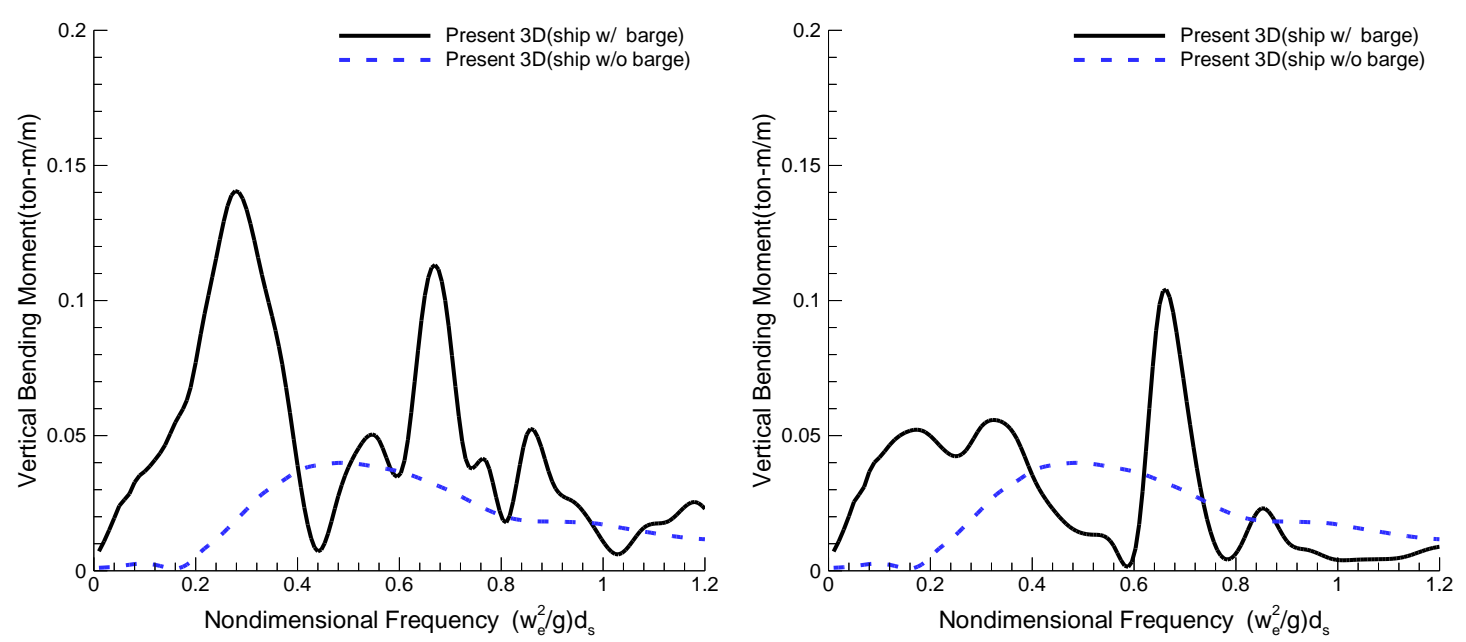

Fig. 18. Vertical Bending Moment for ship with and without barge at $\beta=45^{\circ}, \beta=-45^{\circ}$
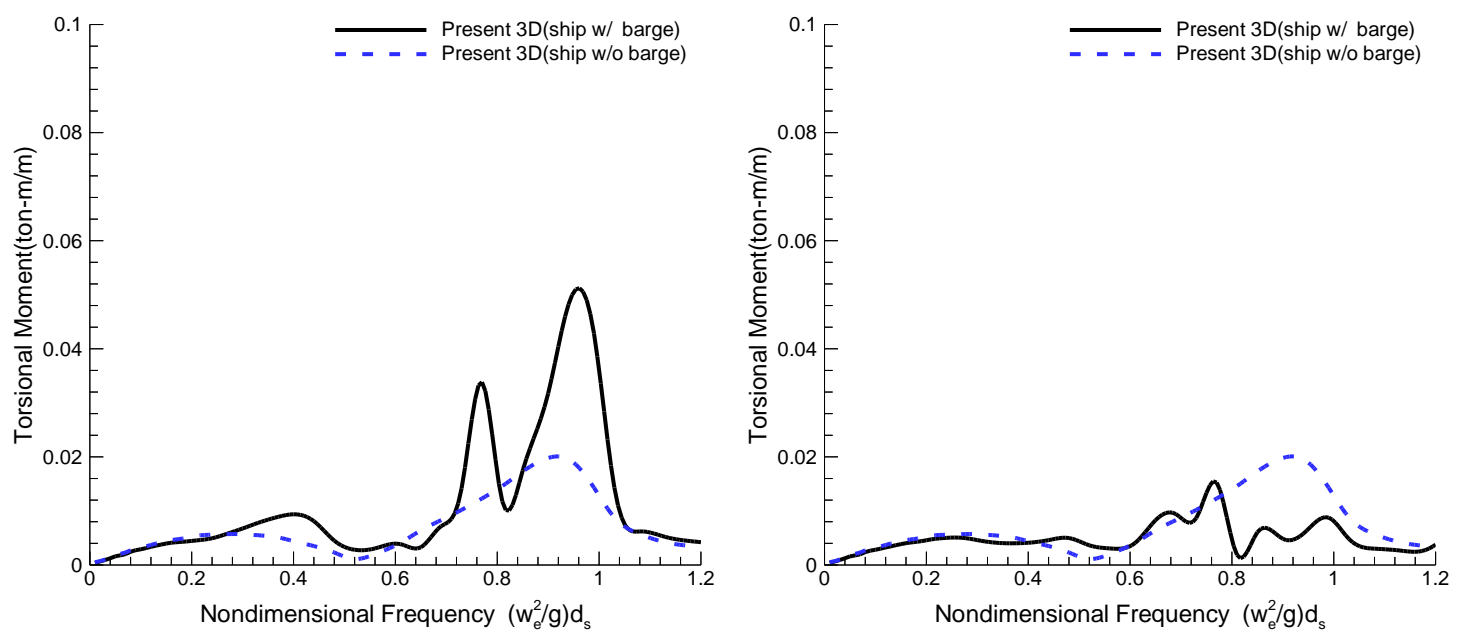

Fig. 19. Torsional Moment for ship with and without barge at $\beta=45^{\circ}, \beta=-45^{\circ}$ 

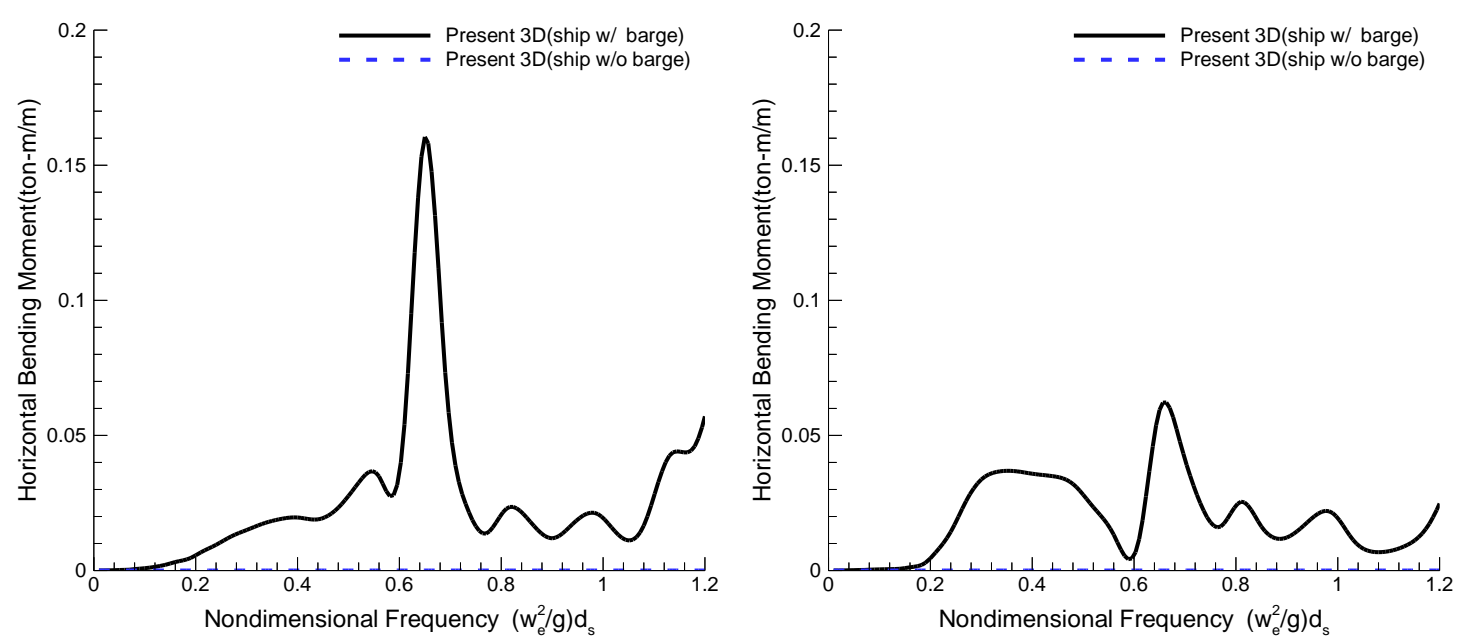

Fig. 20. Horizontal Bending Moment for ship with and without barge at $\beta=180^{\circ}, \beta=0^{\circ}$
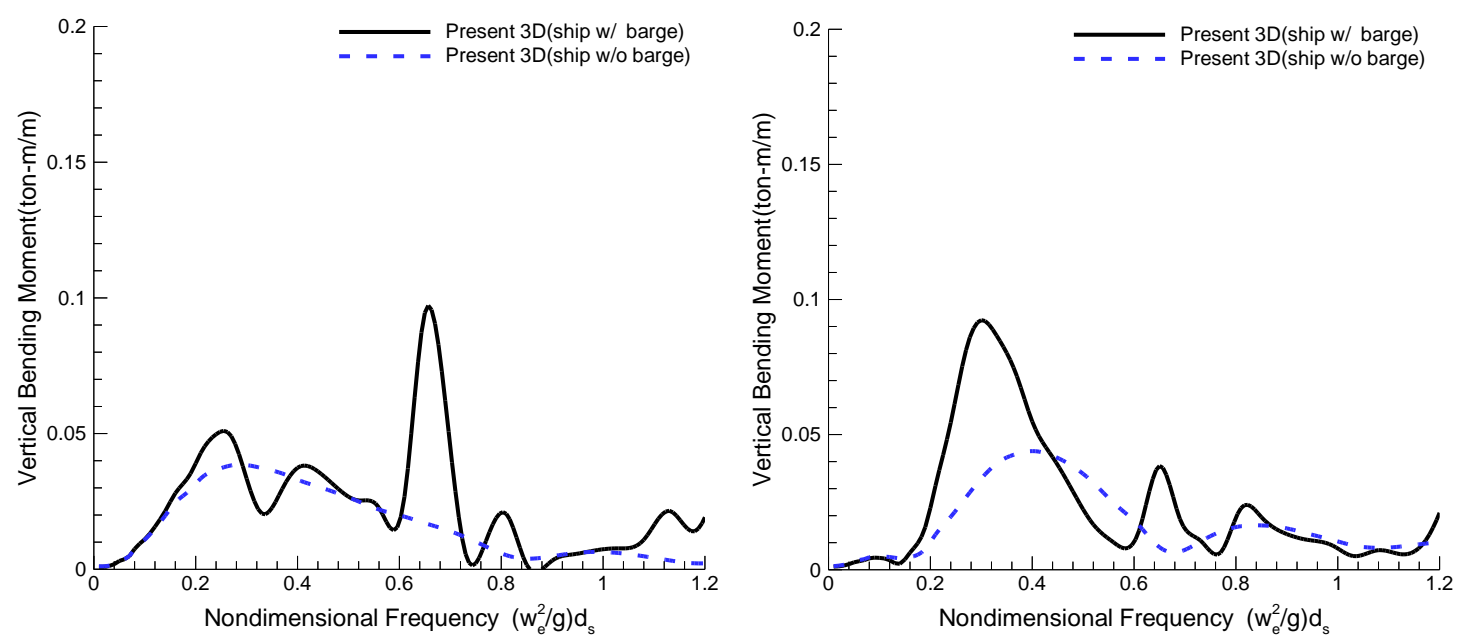

Fig. 21. Vertical Bending Moment for ship with and without barge at $\beta=180^{\circ}, \beta=0^{\circ}$
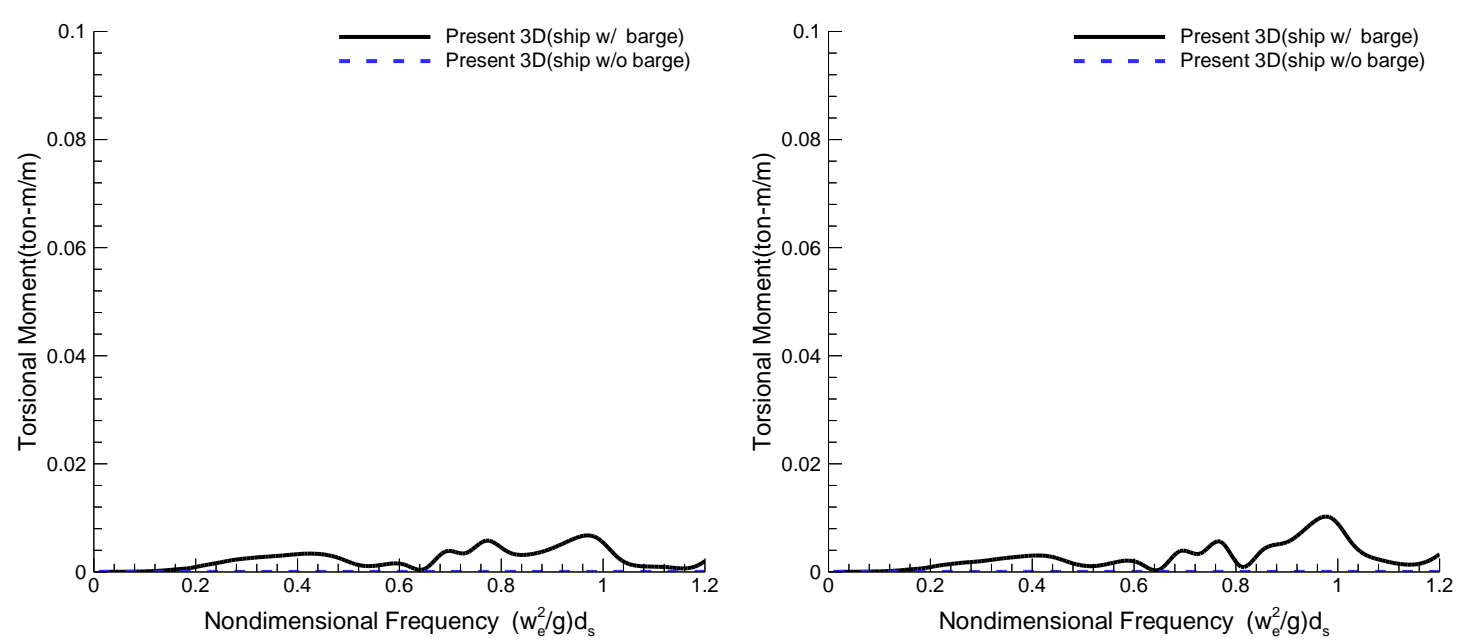

Fig. 22. Torsional Moment for ship with and without barge at $\beta=180^{\circ}, \beta=0^{\circ}$ 


\subsection{Wave induced second order force and moment between two barges}

The comparisons are performed to validate the program for Pinkster [20]'s experimental results. The numerical results of motion response and drift forces are presented in Fig. 23 through Fig. 25. The solid line and circle symbol show the results of the barge alone without another barge.

Fig. 23 shows the surge and sway amplitude at Head and Bow quartering seas, respectively. Because the two barges have same size and dimension, the surge amplitude in head seas have same behavior and hydrodynamic interaction is small.

However, the hydrodynamic interaction effect was shown in sway amplitude at Bow quartering seas despite two barges have same condition. Due to the hydrodynamic interaction between two barges, the motion responses with barge are quite different from the responses of a single barge alone. The motion response of the barge is smaller on the leeside than on the weather side because barge B obstructs the wave exciting force of barge A.

Fig. 24 and 25 show the surge, sway and yaw drift force and moment in Head and Bow quartering seas, respectively. One of the interesting phenomena on two-body motion problem that interaction effect was found in head sea, where no sway and yaw drift forces and moment occur if the barge is floating alone. Because the two barges have same size and dimension, the surge drift force in head seas is same behavior and hydrodynamic interaction is small like the motion response. From the results, we find that two barges drift away against each other, that are barge A moves to the positive $\mathrm{y}$-axis direction and barge $\mathrm{B}$ moves to the negative y-axis, and the drift force for two barges is same. This implies that the results seem to be physically reasonable. If the LNG-FPSO contains turret system to control the bow-heading angle against the incident waves, the dominant waves are head and bow quartering seas since LNG-FPSO weather vane along wave heading. However, the high stiffened mooring lines between two floating structures to endure the wave drift force and moment in head and bow quartering seas will solve this problem.
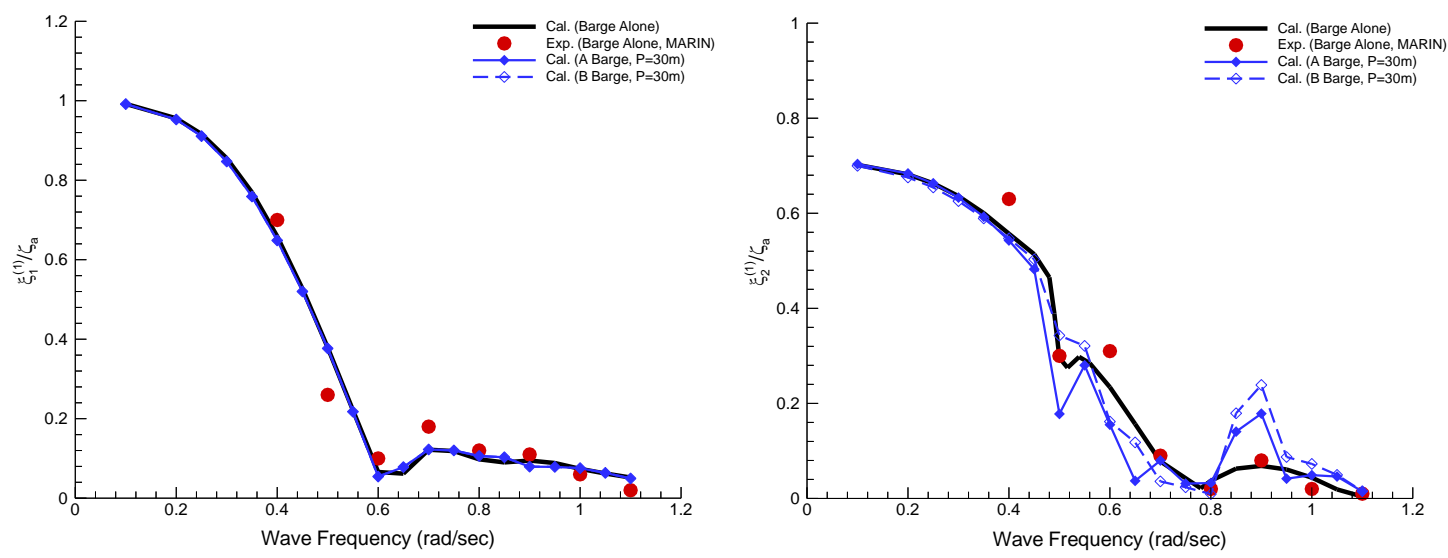

Fig. 23. Surge motion amplitude at $\beta=180^{\circ}$ and Sway motion amplitude at $\beta=135^{\circ}$ 

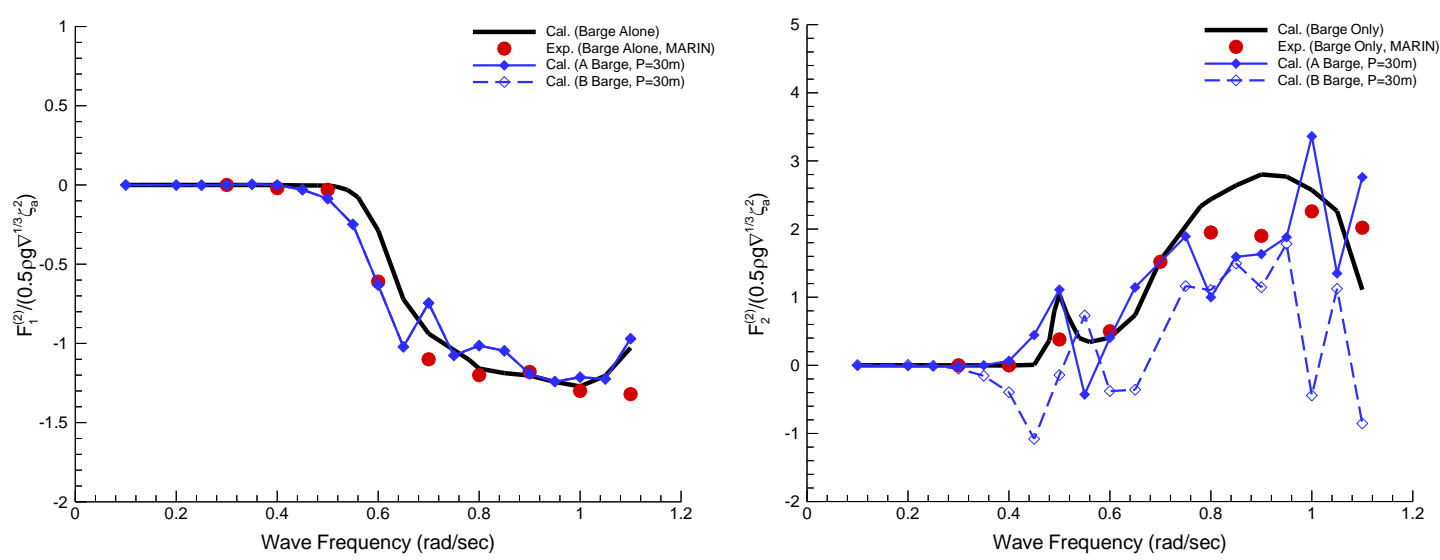

Fig. 24. Surge drift force at $\beta=180^{\circ}$ and Sway drift force at $\beta=135^{\circ}$
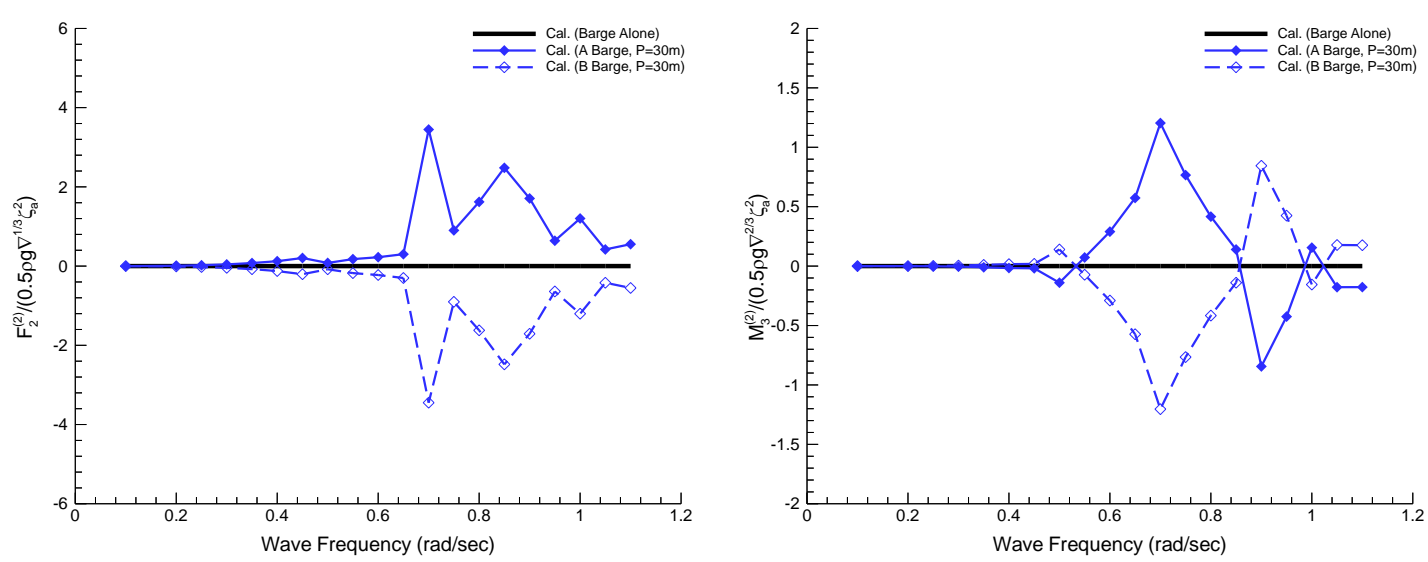

Fig. 25. Sway drift force at $\beta=180^{\circ}$ and Yaw drift moment at $\beta=180^{\circ}$

\section{Conclusions}

In this present paper, the numerical predictions are described on the hydrodynamic pressure distributions, wave exciting forces, coupled motion responses, wave induced structural loads and second order drift forces between two offshore floating structures including the hydrodynamic interaction effect in various heading waves.

In order to validate the developed motion program between two floating structures, we performed the comparison study for the well-known rectangular barge and conventional ship model. Generally, the numerical calculation results give a good correlation with the experimental results and also with other numerical results.

According to the present numerical study, the motion response, wave loads including second order drift forces between two floating structures due to the hydrodynamic interaction effect can be quite significant phenomena during offloading operation. This hydrodynamic interaction effect between two floating structures comes from the incident waves scattering and radiate waves due to the presence of neighborhood floating structures.

Therefore, the motion analysis including the hydrodynamic interaction effect between two floating structures during offloading operations is needed for the more safe offloading operability and also should be applied to the offloading system design to avoid the undesirable large motions at the connected loading arm. 
Also, the optimum separation distance of these multiple floating structures during offloading should be carefully designed (Kim and Ha, [13]) to avoid the unnecessary large motions between two floating bodies.

As a result, the present developed numerical calculation program can be used effectively to predict the wave exciting forces, motion responses, relative motions, first and second order wave loads for multiple floating structures in various heading waves.

\section{ACKNOWLEDGEMENT}

The first author wishes to express his appreciation to Prof. Ho Hwan Chun, President of Pusan National University, Korea for his encouragement and advice during this research. In addition, a sincere thanks to Dr. Jin Ho Lee and Dr. Jong Jin Park in Maritime Research Institute of Samsung Heavy Industries, Korea for their kindness review and comment of this paper. This work was supported by the National Research Foundation of Korea(NRF) grant funded by the Korea government(MSIT) through GCRC-SOP (No. 2011-0030013) and the Ministry of Trade, Industry \& Energy (Republic of Korea) under Industrial Technology Innovation Program (No. 10063405).

\section{REFERENCES}

[1] Ohkusu, M., 1974, Ship Motions in Vicinity of a Structure, Proc. of Int'l Conf. On Behavior of Offshore Structure, NIT, Trondheim, Vol. 1, pp.284-306.

[2] Kodan, N., 1984, The Motions of Adjacent Floating Structures in Oblique Waves, Proc. 3rd. Offshore Mechanics \& Arctic Engineering, New Orleans, Vol. 1, pp.206-213.

[3] Van Oortmerssen, G., 1979, Hydrodynamic Interaction between Two Structures of floating in Waves, Proc. BOSS '79. 2nd Int'l Conf. of Behaviour of Offshore Structures, London.

[4] Loken, A. E., 1981, Hydrodynamic interaction between several floating bodies of arbitrary form in Waves, Proc. of Int'1 Symposium on Hydrodynamics in Ocean Engineering, NIT, Trondheim, Vol. 2, pp.745-779.

[5] Fang, M. C. and Kim, C. H., 1986, Hydrodynamically Coupled Motions of Two Ships Advancing in Oblique Waves, Journal of Ship Research, Vol. 30, No. 3, pp.159-171.

[6] Fang, M. C. and Chen, G. R., 2001, The Relative Motion and Wave Elevation between Two Floating Structures in Waves, Proc. 11th. ISOPE 2001, pp.361-368.

[7] Fang, M. C. and Chen, G. R., 2002, On Three-Dimensional Solutions of Drift Forces and Moments between Two Ships in Waves, Journal of Ship Research, Vol. 46, No. 4, pp.280-288.

[8] Inoue, Y. and Ali, M. T., 2003, A numerical investigation on the behavior multiple floating bodies of arbitrary arrangements in regular waves, Proc. of the 13th Int'l Offshore and Polar Engineering Conference, pp. 558-565.

[9] Buchner, B., van Dijk, A. and Wilde, J.J. de, 2001, Numerical multiple body simulations of side by side mooring to and FPSO, Proc. of the 11th Int'l Offshore and Polar Engineering Conference, pp 343-353.

[10] Choi, Y.R. and Hong, S.Y., 2002, An Analysis of Hydrodynamic Interaction of Floating Multi-Body Using Higher-Order Boundary Element Method, Proc. of the 12th Int'l Offshore and Polar Engineering Conference, pp 303-308.

[11] Kim, K.H., Kim, Y. H., Kim, M. S., 2009, Numerical Analysis on Motion Responses of Adjacent Multiple Floating Bodies by Using Rankine Panel Method", International Journal of Offshore and Polar Engineering, Vol. 19(2), pp. 90-96.

[12] Abyn H., Rafiqul M., Maimun A., Mahmoudi A. and Kato J., 2016, Experimental Study of Motions of Two Floating Offshore Structures in Waves, Brodogradnja/Shipbuilding, Vol. 67(2), pp. 1-13. https://doi.org/10.21278/brod67201.

[13] Kim, M.S. and Ha, M.K., 2002, Prediction of Motion Responses between Two Offshore Floating Structures in Waves, Journal of Ship and Ocean Technology, SOTECH, Vol. 6, No. 3, pp 13-25. 
[14] Kim, M.S. and Ha, M.K., 2003, Relative Motions between LNG-FPSO and Side-by-Side positioned LNG carrier in Waves, Proc. of the 13th Int'l Offshore and Polar Engineering Conference, pp 210-217.

[15] Ha M. K. and Kim M. S. et al, 2004, "First- and Second-order Hydrodynamic Forces and Moments on Two Offshore Floating Structures in Waves", Proc. 14th ISOPE Conference, Toulon, France.

[16] Kim, M. S., 2017, Study on Relative Motion and reduction method for FLNG, Ph.D Thesis (written in Korean), Pusan National University.

[17] Newman, J. N., 1994, Wave effects on deformable bodies, Applied Ocean Research, Vol. 16, pp. 47-59. https://doi.org/10.1016/0141-1187(94)90013-2.

[18] Malenica S., Orozco J.M. and Chen X.B., 2005, Some aspects of multibody interactions in seakeeping, 15th ISOPE Conf., Seoul, Korea.

[19] Zalar M, Malenica Š, Diebold L., 2006, Selected Hydrodynamic Issues in Design of Large LNG Carriers, RINA ICSOT, Conference, Busan, South Korea.

[20] Pinkster, J. A., 1980, Low Frequency Second Order Wave Exciting Forces on Floating Structures, PhDthesis, Delft University of Technology.

[21] Chen, X. B., 2005, Hydrodynamic Analysis for Offshore LNG Terminals, $2^{\text {nd }}$ Offshore Hydrodynamic Symposium, Rio de Janeiro, Brazil.

[22] Pauw, W. H., Huijsmans, R.H.M. and Voogt, A.J., 2007, Advances in the hydrodynamics of side by side moored vessels, Offshore Mechanics and Artic Engineering Symposium, OMAE, San Diego, USA.

[23] Haskind, M.D., 1962, The Exciting Forces and Wetting of Ships in Waves, NSRDC Translation No. 307.

[24] Telste, J. G. and Noblesse, F., 1986, Numerical evaluation of the Green function of water wave radiation and diffraction, Journal of Ship Research, Vol. 30, No.2, pp.69-84.

[25] Salvesen, N., Tuck E. O. and Faltinsen O. M., 1970, Ship Motions and Sea Loads, Trans. SNAME, Vol.78, pp.250-287.

[26] Chan, H. S., 1992, Dynamic Structural Responses of a Mono-Hull Vessel to Regular Waves, Int'l Shipbuild. Progr., Vol.39, No. 419, pp.287-315.

[27] Chen, G. R. and Fang, M. C., 2000, Three-Dimensional Solutions of Exciting Forces between Two Ships in Waves, Int'l Shipbuild. Progr., Vol.47, No. 451, pp.397-420.

Submitted: $12.02 .2018 . \quad$ Mun Sung Kim

Offshore Engineering Team, Samsung Heavy Industries,

Accepted: $18.07 .2018 . \quad$ Co. Ltd, Gyeonggi do, Republic of Korea

Sung Boo Park

Kwang Hyo Jung, kjung@pusan.ac.kr

Department of Naval Architecture and Ocean Engineering,

Pusan National University, Busan, Republic of Korea 